\title{
A Review on Metamaterials for Device Applications
}

\author{
N. Suresh Kumar ${ }^{1} \mathbb{D}$, K. Chandra Babu Naidu ${ }^{2, *}$, Prasun Banerjee ${ }^{3} \mathbb{D}$, T. Anil Babu ${ }^{2}$ and B. Venkata Shiva Reddy ${ }^{2,4}$ \\ 1 Department of Physics, JNTUA College of Engineering, Anantapuramu 515002, India; \\ sureshmsc6.physics@jntua.ac.in \\ 2 Department of Physics, Gandhi Institute of Technology and Management (GITAM) Deemed to be University, \\ Bangalore 562163, India; atadiboy@gitam.edu (T.A.B.); 321962704001@gitam.in (B.V.S.R.) \\ 3 Multiferroic and Magnetic Materials Research Laboratory (MMMRL), Gandhi Institute of Technology and \\ Management (GITAM) Deemed to be University, Bangalore 562163, India; pbanerje@gitam.edu \\ 4 Department of Physics, The National College, Bagepalli 561207, India \\ * Correspondence: ckadiyal@gitam.edu
}

check for updates

Citation: Suresh Kumar, N.; Naidu, K.C.B.; Banerjee, P.; Anil Babu, T.; Venkata Shiva Reddy, B. A Review on Metamaterials for Device Applications. Crystals 2021, 11, 518. https:// doi.org/10.3390/cryst11050518

Academic Editors: Yuri Kivshar, Raghvendra Singh Yadav,

Anju Deswal and Kottakkaran Sooppy Nisar

Received: 12 March 2021

Accepted: 30 April 2021

Published: 7 May 2021

Publisher's Note: MDPI stays neutral with regard to jurisdictional claims in published maps and institutional affiliations.

Copyright: (c) 2021 by the authors. Licensee MDPI, Basel, Switzerland. This article is an open access article distributed under the terms and conditions of the Creative Commons Attribution (CC BY) license (https:/ / creativecommons.org/licenses/by/ $4.0 /)$.

\begin{abstract}
Metamaterials are the major type of artificially engineered materials which exhibit naturally unobtainable properties according to how their microarchitectures are engineered. Owing to their unique and controllable effective properties, including electric permittivity and magnetic permeability, the metamaterials play a vital role in the development of meta-devices. Therefore, the recent research has mainly focused on shifting towards achieving tunable, switchable, nonlinear, and sensing functionalities. In this review, we summarize the recent progress in terahertz, microwave electromagnetic, and photonic metamaterials, and their applications. The review also encompasses the role of metamaterials in the advancement of microwave sensors, photonic devices, antennas, energy harvesting, and superconducting quantum interference devices (SQUIDs).
\end{abstract}

Keywords: metamaterials; electronic materials; electromagnetic; Fano resonances; SQUID

\section{Introduction}

In the modern society, we are surrounded by an amazing variety of materials, such as polymers, ceramics, composites, high strength alloys, superalloys, and so on. Naturally, existing materials possess some properties. However, one can change or modify the naturally occurring properties by altering the microstructure of the materials. The resultant materials are also called as the engineered materials. Recently, the engineered materials have gained much attention by researchers. The engineered materials exhibit better performance, such as large cyclic life, broad temperature ranges, lighter in weight, etc., than conventional materials. There exist numerous engineered materials such as metal-matrix composites, polymer-based composites, piezoelectric materials, magnetostrictive materials, metamaterials, etc. Owing to their large lifetime and high performance, these materials are significantly used almost in all fields of science and engineering. In this article, we have focused on metamaterials and their applications.

\section{Metamaterials}

In Greek, the word meta means "beyond". The metamaterials are new class of engineered materials which exhibit unusual electromagnetic properties that do not occur in natural materials. In general, natural materials like diamond, glass, etc., have positive refractive index, magnetic permeability, and electrical permittivity. Whereas these new engineered materials show negative index of refraction, negative electrical permittivity, and magnetic susceptibility. The metamaterials are also called as left-handed (LH) materials or backward wave (BW) media or negative index materials (NIM) or double negative (DNG) media. In addition, metamaterials have some special properties such as perfect lensing [1], classical electromagnetically induced transparency [2-5], cloaking capability [6], high frequency magnetism [7], dynamic modulation of Terahertz $(\mathrm{THz})$ radiation [8], reverse 
Doppler effect, and reverse Cerenkov effect [9]. These unique properties of metamaterials enable them to fabricate functional devices with switching and tuning capabilities [10-14]. Further, based on the permittivity and the permeability, the metamaterials are categorized as mu-negative material (MNG), epsilon negative material (ENG), double positive material (DPS), and double negative material (DNG) [15]. The MNG and ENG are also called as single negative materials. Whereas the double negative and double positive materials can be engineered at particular frequency band. In the year 1968, Victor Veselago, who is a Russian physicist, first theoretically proposed the metamaterials [16]. He theoretically explored the electrodynamics of the materials with negative values of the magnetic permeability $(\mu)$ and relative permittivity $(\epsilon)$. Moreover, the propagation of electromagnetic waves is discussed in those materials. Nevertheless Smith et al. practically demonstrated for first time a structure which exhibits negative refraction in the microwave region [15]. In addition, J.B. Pendry et al. [17] fabricated the first metamaterial by two interpenetrating subsystems. Particularly, by using an array of thin metallic (copper) wires and rings, they fabricated split ring resonators (SRRs), which provide negative values of permittivity and permeability [17-19]. In metamaterials, the split rings play the role of atoms in natural materials and act as electrically small resonant particles which contribute negative permeability. Herein, copper wire contributes negative permittivity. Combined array exhibits negative permeability and permittivity. Figure 1 gives the pictorial representation of a metamaterial [20] (Figure taken from ref. [20]). Later, Ziolkowski [21] reported another metamaterial which consists of substrate entrenched with capacitively loaded strips (CLSs) and square SRRs. In this material, capacitively loaded strips gives a strong response to electric fields and gives negative $\epsilon$ and SRRs interacts with magnetic fields and provides negative $\mu$. Afterwards, numerous researchers designed and fabricated different metamaterials by using different methods like shadow mask/etching, clean room etching, etc., in many frequency bands. In addition, based on the presence of SRRs, the metamaterials are available in various forms. That means the metamaterials consisting SRRs are available in one, two, and three dimensions [22-25]. Further, those metamaterials without SRRs (for example, fishnet structure) are available in two, quasi-two, and three dimensions [26-29]. Hence, owing to their unique properties and structures, the metamaterials find their applications in various devices such as sensors [30-32], superlens [33], antennas [34,35], superconductors [36], absorbers [37-42], energy harvesting [43,44], etc. In this article, we have concentrated on recently developed metamaterials and their applications.

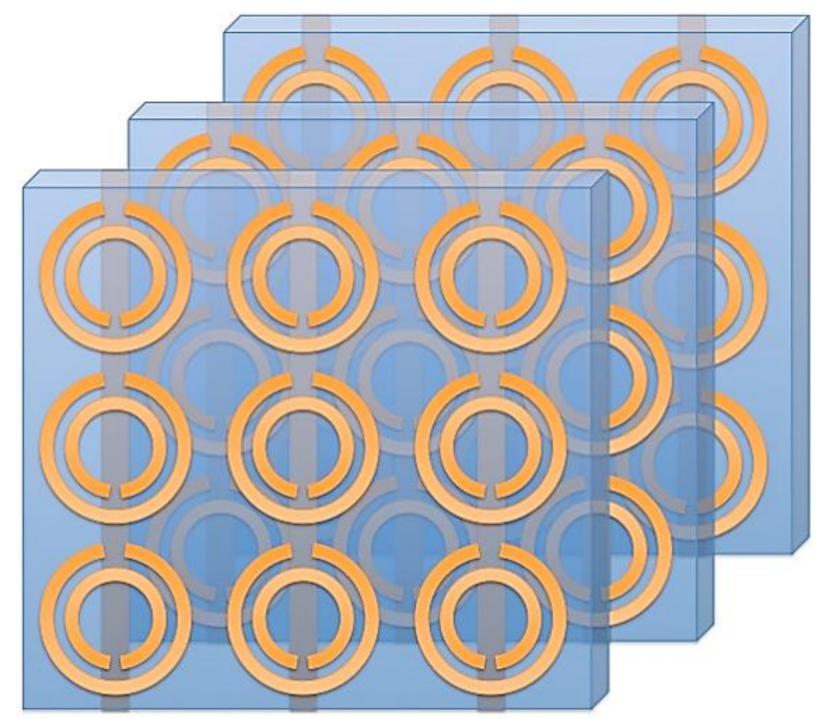

Figure 1. Pictorial representation of a metamaterial [20]. 


\section{Applications of Metamaterials}

As we know, the metamaterials are engineered metamaterials which exhibit exceptional properties that cannot be found naturally. In metamaterials, the resonant nature of the atoms leads to the enhancement in light matter interaction that affords dramatic changes in the light properties [45]. Especially, chiral metamaterials give strong response to light, this chiroptical response surpasses the natural materials. Owing to these special properties, the chiral meta devices have potential applications in polarization sensitive nano optical devices [46,47]. For instance, 3D nanoarchitecture generally exhibit chiroptical response [48,49], which are widely used for fast polarization switching [50]. Compared to bulk materials, the metamaterials or metasurfaces show domination in controlling the amplitude, phase, and polarization of light. In recent years, researchers have concentrated on achieving strong chiroptical responses in metasurfaces by breaking the rotational symmetries at unit cell level [51-55]. In this regard, 2D patterned layer of chiral metamirrors present a decent light matter interaction [53,54]. In addition, the metal/dielectric/metal sandwich structures display improved chiroptical responses. Recently, Kang et al. [56] demonstrated an ultrathin nonlinear chiral meta mirror. The proposed metamirror consists an array of SRRs made up of amorphous silicon $(\alpha-\mathrm{Si})$. They reported that the metamirror exhibit fast optical polarization switching (picosecond) of near infrared light at pump energies of picojoule per resonator. This can be achieved by strong chiroptic response of the atoms in the proposed mirror. Hence the chiral metamirrors are promising candidates for power efficient and high-speed polarization state modulators in optical information processing.

Further, it is important to guide the waves for reliable transportation of information through a physical channel. But, due to attenuation and back-scattering, the transportation of energy is sensitive to sharp turns and defects in high frequency systems such as signal processing $[57,58]$. However, in matter systems topological phenomenon is considered for unidirectional and attenuation free energy transportation [59]. Moreover, the topological metamaterials can transport the energy effectively, which is called phononic energy transportation. Till now, the mechanical metamaterials are being used in large scale systems such as gyroscopic lattices [60,61], arrays of pendulums [62,63], structured plates [64], and so on. For utilizing the mechanical materials in high frequency energy transportation, the metamaterial topological systems must be scaled on to the chip level $[65,66]$. In this view, Cha et al. [67] proposed topological nanoelectromechanical metamaterials. The proposed metamaterials consist of 2D array of free-standing SiN nanomembranes which can operate at high frequencies of 10-20 MHz. They also demonstrated the presence of edge states and frequency dispersion. Finally, the proposed on-chip topological metamaterials are suitable for high frequency signal processing applications.

Furthermore, Cho et al. [68] proposed the concept of virtualized metamaterials to overcome the shortcomings of traditional metamaterials. Through engineered resonant modes with structured atoms the metamaterials permit to attain constitutive parameters beyond their natural range. Generally, the tunability of constitutive parameters in real time applications is a fundamental challenge in traditional metamaterials. This can overcome by the proposed concept of virtualized metamaterials. In addition, they reported that the replacement of the physical structure with designed fast signal processing Kernel circuit. The circuit allows exhibiting defined frequency dispersion through which one can control mass density and bulk modulus of the metamaterials. In addition, the proposed concept is helpful in designing topological, non-Hermitian, and non-reciprocal systems by tuning the frequency, dispersion, and amplitude for fast signal processing applications.

Afterwards, the fluorescent resonant energy transfer (FRET) [69,70] between the donor and acceptor enhances the efficiency of solar cells [71], organic light emitting diodes [72], photosynthesis [73], and so on. Nevertheless, in case of direct dipole-dipole interaction, the resonance energy transfer occurs only at very short distances of $10 \mathrm{~nm}$, beyond this distance efficiency of the energy transfer decreases significantly. This is one of the major limitations of transportation of energy in solar cells. Continuous research efforts are going on to enhance the efficiency of the energy transportation by using hyperbolic metamateri- 
als [74,75], plasmonic nanostructures [76,77], and planar silver films [78]. Especially, the optical topological transition (OTT) in a metamaterial theoretically considered the ideal model for the enhancing energy transfer over long range orders [79]. In this regard, recently Deshmukh et al. [80] demonstrated the long range (about $160 \mathrm{~nm}$ ) direct energy transfer between the donor $\mathrm{CdSe} / \mathrm{ZnS}$ core-shell quantum dots and acceptor $\mathrm{Cy} 3$ organic dye molecules by using OTT in a metamaterial. They reported that the metamaterial consists the alternating layers of germanium $(\mathrm{Ge})$ deposited silver $(\mathrm{Ag})$ and alumina $\left(\mathrm{Al}_{2} \mathrm{O}_{3}\right)$. The OTT in the metamaterial alters the density of states between donor and acceptor, which leads to the long-range energy transfer with $32 \%$ transfer efficiency. Further the experimental values are in good agreement with theoretical values. Finally, they concluded that the OTT in metamaterials enhances the efficiency of energy transportation and controls the transfer process. Owing to this, the OTT in metamaterials have potential applications in numerous fields such as organic solar cells, quantum entanglement, etc.

In addition, the hyperbolic metamaterials are also gained considerable attention. A hyperbolic metamaterial is a special type of anisotropic metamaterial whose isofrequency contour (IFC) takes the form of an open hyperboloid because the principal components of its electric or magnetic tensor have opposite signs [81-84]. The unusual nature of IFC enables the hyperbolic metamaterials to be used for controlling the electromagnetic waves in new ways. Through controlling the shape of the hyperbolic dispersion, one can flexibly control the propagation of light in hyperbolic metamaterial, resulting abnormal scattering [85-88] splitting [89-91], all angle negative refraction [92-96], etc. These hyperbolic metamaterials are also called indefinite media $[97,98]$ or polaritonic crystal in which the coupled states of matter and light give rise to a larger bulk density of electromagnetic states [99,100]. Owing to this, hyperbolic metamaterial possesses strong enhancement of spontaneous emission [101-105] and Cherenkov emission with low energy electrons [106-109]. These hyperbolic metamaterials can be used in multifunctional platform for sensing, quantum engineering, waveguiding, super resolution imaging, and so on [110,111]. At first, the hyperbolic nature of metamaterial is first observed in microwave region. The natural as well as engineered material exhibits the hyperbolic dispersion. In infrared and visible region, some natural materials such as $\mathrm{SiC}$, graphite, $\mathrm{Bi}_{2} \mathrm{Se}_{3}$, etc., exhibit the hyperbolic dispersion due to excitation of phonon polaritons [112-118]. Similarly, the engineered structures such as multilayer fishnets [119], uniaxial metasurfaces [120,121], and metal-dielectric structures $[122,123]$ have subwavelength unit cells that display the hyperbolic dispersion. The dispersion manipulation in hyperbolic metamaterials can be used in many applications like sub-diffraction imaging [124], sub-wavelength modes [125], thermal emission engineering [126-128], high sensitivity sensors, hyper lens, etc. Therefore, the hyperbolic metamaterials with unusual properties will play a significant role in the advancement of novel optical devices in future. Recently, Schoche et al. [129] reported the behaviour of tunable hyperbolic metamaterials which are derived from self-assembled carbon nanotubes. To obtain the hyperbolic metamaterials from carbon nanotubes, they employed the Muller matrix ellipsometry over the broad spectral range from mid-IR to UV region to specify the dielectric tensor function on high dense films consisting single wall carbon nanotubes. Optically these films are anisotropic and act as metamaterials with effective medium response. Further, an oscillator model developed from the proposed metamaterials exhibit broad range of hyperbolic dispersion compared to film consisting unordered carbon nanotubes. Hence, the aligned carbon nanotubes form the metamaterial and play a prominent role in accomplishing tunable hyperbolic nature.

In addition, with the help of face-to-face SRRs and a central bar Hu et al. [130] demonstrated the design of tunable terahertz metamaterial (TTM) for switching applications. They reported that, the free spectrum ranges (FSR) of TTM varies bi-directionally, i.e., broadened, and shortened with respect to variation of gap between SSR and central bar. In TE mode, FSR is broadened by $0.14 \mathrm{THz}$ (from 0.65 to $0.79 \mathrm{THz}$ ), whereas in TM mode it is shortened by $0.19 \mathrm{THz}$ (from 0.30 to $0.19 \mathrm{THz}$ ). Moreover, TTM shows the dependence of polarization when it is subjected to external electromagnetic radiation. Moreover, in both 
single band and dual band proposed TTM acts like switch at TE mode, whereas at TM mode, the resonance of TTM insensitive to the displacement of central bar. Owing to this the proposed TTM can be utilized as switch in terahertz frequency range.

$\mathrm{Li}$ and Cheng [131] proposed a temperature tunable metamaterial absorber (MMA) by using two stacked square shaped strontium titanate resonator structures (STOs) and copper substrate. From the analysis of simulation studies, they reported that, at specific frequencies, i.e., $0.114 \mathrm{THz}$ and $0.181 \mathrm{THz}$ in terahertz region the reflectance of the proposed MMA is about $2.1 \%$ and $0.2 \%$ at room temperature. Moreover, it has maximum absorption peaks 97.9 and $99.8 \%$ at the same frequencies. In addition, owing to symmetry of unit cell structure STO based MMA shows polarization insensitive nature to both transverse electric and transverse magnetic modes. Further, the distribution studies of power flow and electromagnetic fields disclosed that, the excitations of fundamental dipole modes in the MMA are the origin of the high level of absorption. In addition, the absorbance of the proposed MMA can be altered by varying the external temperature and, by varying its structural parameters. Owing to the excellent characteristics, the proposed STO-based MMA may have potential prospects in thermal imaging, temperature sensing, thermal emission, etc. In addition, scientists designed strontium titanate (STO) based single band tunable metamaterial absorber [131]. They reported that, with respect to structural parameters, absorption peak is increased and resonant frequency is reduced. This means the absorption peaks are enhanced from 90 to $99.4 \%$, whereas the resonant frequency is shifted from 6.2 to $5.8 \mathrm{THz}$. As the temperature is increased from 300 to $380 \mathrm{~K}$ the absorption peak shows $2 \%$ decrement. While the resonant frequency shifted from 6.2 to $7.1 \mathrm{THz}$. So, the proposed metamaterial can be tuned by temperature. Moreover, the temperature tunable metamaterial exhibits the excellent absorption property.

Next, using four L-shaped anisotropic metamaterials Lu et al. [132] demonstrated an ultrathin reflective linear polarization converter. The proposed design can convert the linearly polarized radiation to cross polarized radiation with the conversion ratio of $98 \%$ from 4.2 to $5.2 \mathrm{THz}$. In addition, the reflection coefficient of cross polarization is greatly influenced by the deflection angles relative to y-axis [133]. So, the proposed metamaterialbased device can be useful for the manipulation of polarization in optical instruments. In recent years, planar metamaterials are studied extensively owing to their potential applications in design of lasing spacers, flat optical components, nonlinear devices, etc. In these metamaterials high Q-factor (quality factor) is essen26GH26tial for enabling strong light-matter coupling $[134,135]$. In this regard, the Fano resonances support the narrow linewidths with high Q-factor values [136-138]. The Fano resonance in metasurfaces is originated from increased electric field in the subwavelength capacitive gaps of symmetry broken resonators. Earlier the Fano resonance is modulated by changing the coupling distance in the unit cell or changing the asymmetry parameters of the unit cell [139-141]. But, in this technique the Fano resonance works in passive mode. Therefore, the researchers searched for an alternative design for active control of metasurfaces. They suggested that active control is possible by controlling the conductivity of the Fano structure. Until now, very less work has been done on the Fano structures [142-145]. In this connection, Ma et al. [146] demonstrated an active switching of extremely large Q-factor Fano resonance by using $\mathrm{VO}_{2}$ (vanadium oxide)-implanted $\mathrm{THz}$ asymmetric double $\mathrm{C}$-shaped metamaterial structures. They reported that the double Fano resonances are highly sensitive to the temperatures and, the Fano resonances can be switched at low thermal pumping of $68^{\circ} \mathrm{C}$. The exited Fano resonances in the metadevices can be completely vanished by cooling. However, the tuning of Fano resonances in cooling and heating are different. To understand the internal mechanism of the temperature tuned Fano resonances, at respective resonant frequencies they simulated the distributions of surface current and electric field for high $\left(70{ }^{\circ} \mathrm{C}\right)$ and low $\left(45^{\circ} \mathrm{C}\right)$ temperatures. In addition, at $1.16 \mathrm{THz}$, the resonant linewidth of the proposed device is $0.015 \mathrm{THz}$, and the Q-factor is 98 , which is very high compared to traditional metamaterials. Hence, the proposed temperature tunable Fano resonant devices are promising candidates for designing advanced high-performance photonic 
devices like ultrasensitive temperature sensors. Later, Li et al. [147] reported an active Fano metasurfaces with the help of graphene-based terahertz asymmetric split-ring resonant structure (Gr-TASR) on silicon (Si) substrate. The active control in the proposed design is possible through controlling the conductivity of the graphene by a combination of $\mathrm{CW}$ (continuous wave) illumination and bias voltage. Further, they experimentally observed that, the clear modulation of Fano resonance is achieved by optical illumination with $0.7 \mathrm{Wcm}^{-2}$ power density at very low voltage of about $-0.8 \mathrm{~V}$. This may be due to shorting effect between the capacitive split gaps of Gr-TASR. This is an effective approach for controlling the metamaterials actively with both electrical and optical fields which can play a prominent role in designing of variety of futuristic graphene-silicon based terahertz photonic devices.

Further, Lin et al. [148] demonstrated the design of a tunable terahertz (THz) resonator by using AFSM (asymmetrical F-shaped metamaterial) which is composed of Au-layer fabricated on SOI (silicon-on-insulator) substrate. Figure 2 shows the schematic representation of the proposed F-shaped THz resonator (Figure 1 of Ref. [148]). Without changing the other parameters, they designed three F-shaped resonators of lengths $60 \mu \mathrm{m}, 65 \mu \mathrm{m}$, and $70 \mu \mathrm{m}$. When the proposed resonator is exposed to electromagnetic radiation, it shows the switch function for single band resonance at TM mode and dual band resonance at TE mode. Owing to this one can use the proposed device as a THz switch in TE-mode and as a THz filter in TM-mode. In addition, the tuning resonances are in between 0.2 and $0.4 \mathrm{THz}$ in TE-mode and the resonator having length of $60 \mu \mathrm{m}$ exhibits largest Q-factor of 40. Moreover, at TM-mode, all the proposed resonators show same Q-factor of 20. All the outcomes are evinced that the proposed AFSM device is suitable for designing environmental sensor. They reported that, the proposed device is subjected to surrounding environmental factors with different refractive indices for further enhancement of the flexibility and efficiency. Therefore, this new AFSM device provides a way to enhance the sensitivity of metamaterials in $\mathrm{THz}$ region for polarizer, sensor, and switching applications.

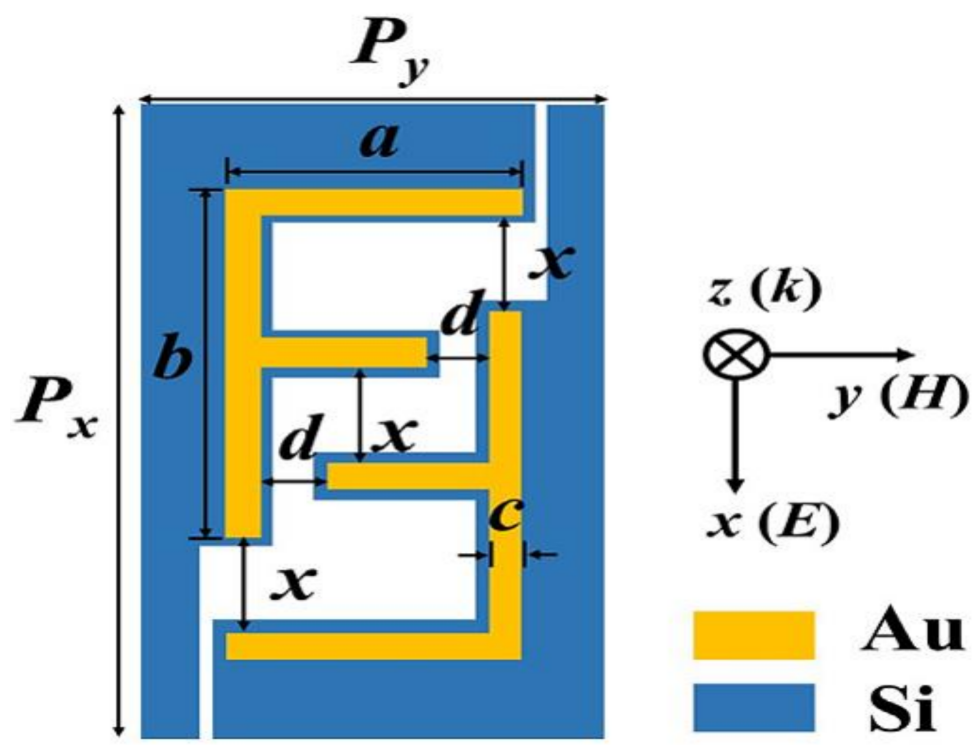

Figure 2. Schematic representation of the F-shaped THz resonator (Figure 1 of Ref. [148]).

\section{Metamaterials in Photonic Devices}

Over past few years, researchers have been searching for highly integrated light source. The photon transparency in metallic photonic crystals which were doped with nanoparticles have been studied by Mahi R Singh; his study used new optical devices like switches and optical transistors [149]. There is a high demand for the development of practical optical photonic devices and its application systems for controlling absorption/transmission/reflection of electromagnetic waves. It was observed that by adjusting 
the graphene fermi level a tunable metamaterial attains electronically reconfigurable terahertz reflection, absorption, and transmission in an effective manner [150]. In this view, various designs for free electron radiation emitters have seen light, which includes light wells [151,152], graphene based plasmonic, and dielectric based undulators [153,154], metallic nano gratings [155], etc. Along with the advancement of narrow linewidth miniaturized lasers [156] and highly integrated electron accelerators [157,158], the progress in nanoscale undulators paves the way toward the realization of X-ray light sources and on-chip extreme ultraviolet (EUV) sources. These advanced sources have promising applications in various fields such as natural sciences, engineering, and medicine [159,160]. Owing to strong confinement, low losses and dynamic tunability, the graphene plasmons are much suitable for manipulation of light matter interaction [161-165]. In addition, highly confined plasmons interact effectively with the matter. Nevertheless, small transverse extent of polaritonic field of such highly confined plasmons limits the interaction. This type of limitation exists in the light matter interaction in micro/nanoscale photonic wavelengths. Such limitations can be conquered by introducing metamaterials. Amongst, various kinds of materials graphene exhibit outstanding optical properties are highly appealing for optoelectronics and energy conversion applications [166-173]. However, the low optical absorption (2.3\%) and ultrathin nature $(3.4 \AA)$ of monolayer graphene over a broadband wavelength limits its ability to provide sufficient optical modulation that restricts the performance in optical applications $[174,175]$. However, the graphene based-metamaterials consisting alternating dielectric layers and graphene can enhance the optical modulation which can be useful in advanced photonic devices [176-178]. Recently, Pizzi et al. [179] reported the enhancement of electron-plasmon interaction area by graphene metamaterials. They found that the output intensity is scaleup by a factor of 580 with respect to single graphene layer. For example, for $5 \mathrm{MeV}$ electrons, a single layer metamaterial having $50 \mu \mathrm{m}$ length and 50 layers, and a beam of current $1.7 \mu \mathrm{A}$ can generate $1.5 \times 10^{7}$ photons. This is due to the ability of the graphene multilayer structures to support MRPs (multilayer resonant plasmons) [180-186]. Further, the layered conducting structures can also be generated the visible Cerenkov radiation [187]. In addition, they reported that through allowing large amount of electron beams, the graphene multilayers produces the significant improvement in output intensities. Based on the conductivity of the graphene, there will be optimum layers in the metamaterial that enhances the intensity of the output. Further, by varying the resonating modes at different laser frequencies, the proposed metamaterials can generate multiple X-ray harmonics, which are used in time-resolved X-ray spectroscopy for ultrafast imaging of chemical reactions and electronic state transitions [188,189]. In addition, Yang et al. [190] suggested a low-cost and transfer free, solution-phase technique for the fabrication of multilayer graphene-based metamaterials. This consists of alternating monolayer graphene oxide/graphene and dielectric layers. They reported that the optical properties of the prepared graphene-based metamaterials can be tuned dynamically by controllable laser mediated conversion. Graphene-enabled active metamaterials may provide new platform for dynamical manipulation of light matter interactions [191]. Figure 3 shows the schematic representation of dynamic process for in situ phototunable graphene based metamaterial (Figure 1 of Ref. [190]). In addition, the laser patterning leads to functional photonic devices like ultrathin flat lenses embedded in the lab-on-chip device. In general, these ultrathin flat lenses maintain consistency and shows subwavelength focusing resolution at ambient environment without any observable degradation compared with the original lens. Therefore, these graphene-based metamaterials provide a new insight for widespread applications in on-chip integrated photonic devices. 


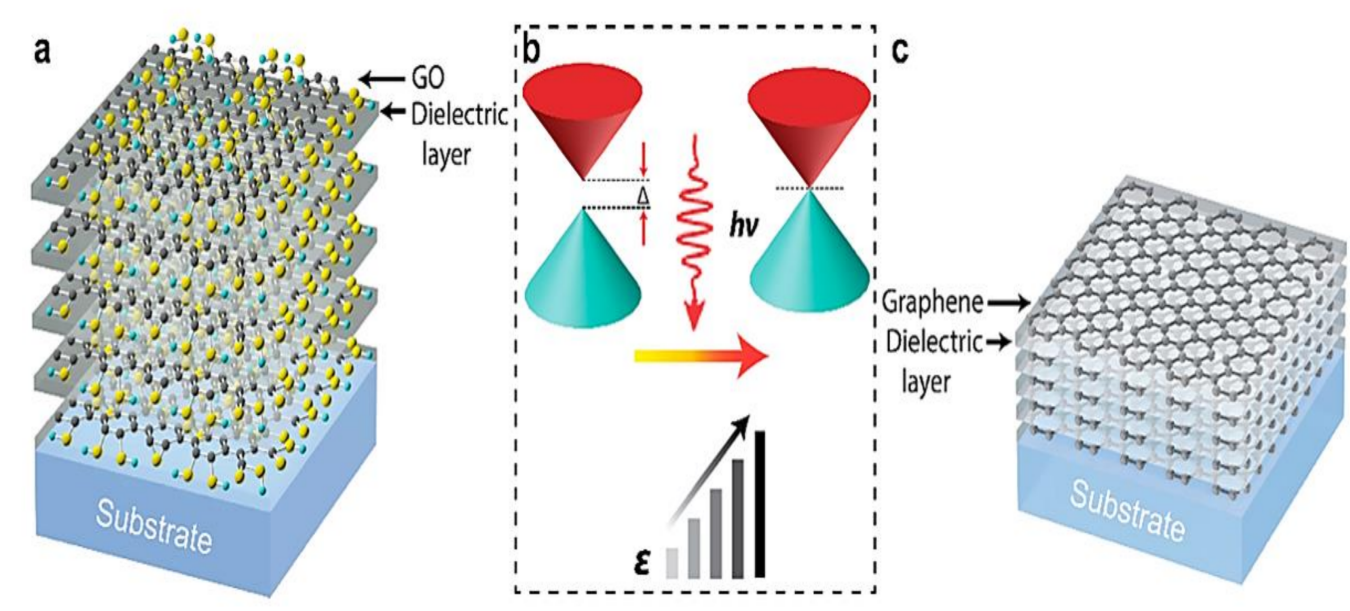

Figure 3. The representation of dynamic process for (a) initial, (b) schematic and (c) final state of in situ phototunable graphene based metamaterial (Figure 1 of Ref. [190]).

\section{Metamaterials in Microwave Sensors}

Nowadays, the characterization and quantification of liquids have become crucial in different fields such as biomedical engineering, agriculture, pharmaceutical, etc. [192-195]. In general, the characteristics of various liquids can be analyzed with the help of their polar nature and specific electrical properties. Moreover, the performance of the microwave devices is greatly influenced by the electrical properties of the liquids. Further, the interaction of the electromagnetic radiation with the polar liquid materials led to variation of the direction of the polarization for different molecules. Especially, microwave sensors employ that kind of interaction to manipulate the dielectric properties of the liquids for characterization. Due to simple procedure, non-invasiveness and quick response, the electromagnetic approach-based sensors offer several advantages than the normal ones. Further, owing to their unique properties the electromagnetic metamaterials gained much attention in the advancement of the electromagnetic devices over last two decades. Recently, the designs based on electromagnetic metamaterials have been employed for microfluidic sensing applications $[196,197]$. These sensors exhibit high sensitivity and strong interaction between the analytes and electric field. However, the requirement of large sample volume is one of the shortcomings of the microfluidic sensors. This can be mitigated by using unit cell resonation structures in microfluidic sensors [198,199]. Still, achieving the significant sensitivity in microlevel is a major problem. To overcome this, numerous researchers are putting their continuous efforts in designing the miniaturized sensors with significant sensitivity and selectivity for consistent characterization of a liquid. In continuing this, $\mathrm{Xu}$ et al. [200] demonstrated a lightweight, low cost, portable, biocompatible, and flexible metamaterial (metaflex) based photonic device for the biological and chemical sensing and high sensitivity strain applications. The device can be operated invisible as well as IR regions. The proposed device consists U-shaped SRRs of $30 \mathrm{~nm}$ thick gold ( $\mathrm{Au}$ ) or silver (Ag) which are deposited on poly(ethylene-naphthalate) substrate with the help of electron beam lithography [201]. In addition, the U-shaped SRRs metamaterials display an electric resonance of $542 \mathrm{~nm}$ and magnetic resonance of $756 \mathrm{~nm}$. Both magnetic and electric resonant modes give highly sensitive response to surrounding dielectric media, bending strain, and surface chemical environment. Owing to coupling of electric and magnetic fields, the proposed metamaterial-based photonic device shows greater response to nonspecific bovine serum albumin protein binding with a shift of magnetic resonance of $4.5 \mathrm{~nm}$. It also shows superior response for self-assembled monolayer of 2-naphthalenethiol with a shift of magnetic resonance of $65 \mathrm{~nm}$. These outcomes suggest that the proposed device is a prominent candidate for chemical and biological sensing. Microwave metamaterials are electromagnetic devices which are synthesized to control microwave fields. These materials can be used as future healthcare systems that can overcome technical restrictions 
after they are interfaced with human body. John S. Ho et al. [202] studied the working principles and applications of microwave metamaterials for biomedical sensing. Further, Kayal et al. [203] demonstrated a compact microwave sensor with the help of mu negative (MNG) metamaterial for liquid characterization. They reported that the prepared sensor exhibits high sensitivity along with noticeable compactness. The square spiral metamaterial (MNG) plays a significant role in accomplishing this sensitivity in small cross-sectional area as well as notable compactness. In addition, the sensing behaviour of the prepared device is confirmed through least square technique followed by development of two nonlinear equations for calibration purpose. These nonlinear equations (Equations (9) and (10) of Ref. [203]) are useful for finding the permittivity of the unknown samples. Hence, the compactness and high sensitivity of the prepared sensor make it a prominent candidate for liquid sensing applications.

In addition, the electromagnetic waves in tera Hertz $(\mathrm{THz})$ region shows sensitive responses to intra and intermolecular vibration modes and low photon energy (few $\mathrm{meV})[204,205]$. Due to this the $\mathrm{THz}$ electromagnetic waves display potential applications in bio-sensing, microscopy, and spectroscopy. In THz region, with the help of tens of metamaterials and graphene, $\mathrm{Xu}$ et al. [206] introduced a platform for bio molecular sensing. Further, by using graphene assisted nano metamaterials, Lee et al. [207] demonstrated a label free sensing technique for discrimination of single-stranded deoxyribonucleic acids (ssDNAs) in THz region. The combination of unusual properties of metamaterial and electrooptical properties of graphene provides biomolecule sensing property even using $\mathrm{THz}$ photons with very low energy. Additionally, they reported that the enhancement of $\mathrm{THz}$ field at resonance frequency causes the rise in absorption cross section of the graphene sheet which in turn provides ultrahigh sensitivity. The sensing mechanism includes the direct transfer of graphene onto a nano-slot metamaterial and tightly binding the targeted DNA molecules without modifying the structure. Here, the nano-slot metamaterials enhance the $\mathrm{THz}$ transmittance which is proportional to the absorption cross-section of DNA adsorbed graphene layer. So, greater number of DNA molecules can be observed through the strongly focused $\mathrm{THz}$ electromagnetic waves. Further, adsorbed molecules change the intrinsic electrical properties of the graphene which can easily be detected. This mechanism is allowed to sense of different biomolecules. Specifically, considering suitable receptor to capture DNA molecules followed by rapid primary screening, finally applied for sequencing the DNA. Hence, the graphene assisted THz metamaterial sensing platform is suitable for biological sensing applications also understanding the electro-optic behaviour of 2D materials.

The sensitivity of the microwave sensor can be enhanced by coupling the transmission lines with metamaterial based open loop resonators [208]. However, during coupling the resonator with transmission line there exist shift in resonant frequency which strongly affects attain high sensitivity. To overcome this, Abdolrazzaghi et al. [209] proposed a novel metamaterial based planar microwave sensor which can be operated at $2.5 \mathrm{GHz}$. They prepared the above proposed sensor by coupling negative refractive indexed metamaterials with transmission lines which exhibits greatly improved resonant properties [210]. Afterwards, they developed the signal flow analysis to estimate the transmission response of the prepared sensor. In comparison with the microstrip or conventional sensor the proposed sensor shows very high sensitivity along with large complex permittivity. They reported that the proposed sensor displays superior properties, particularly in water host medium and high permittivity materials. The concentration measurements of the methanol or ethanol in water medium reveals the outstanding performance of the proposed sensor over conventional sensor. Hence, the proposed metamaterial based planar microwave sensor is useful for characterization of high permittivity materials, highly sensitive concentration measurement of methanol or ethanol in water and also biomolecule detection. 


\section{Metamaterials in Antennas}

In modern era, the communication system is shifting from wired to wireless. In this regard, there is a need for antennas for wireless transmission of signals. Hence, the demand for antennas which are having large operating bandwidth and high gain has increased. The researchers are searching for new kind antennas which satisfy the demand of modern communication. In this concern, DRA (dielectric resonator antenna) attracted much attention owing to its novel features such as high radiation efficiency and broad bandwidth [211-213]. Initially, Long and his coworkers started the experimental investigations on DRAs, followed by many researchers, now the DRAs are available in different shapes like rectangular, gammadion cross, cylindrical, quadruple, spherical, hemispherical, and so on [214-217]. Amongst, rectangular DRA exhibits good attractive properties. However, limited bandwidth and manufacturing cost are the major drawbacks of DRAs. To reduce the fabrication cost, cost effective additive manufacturing (like 3D printing) can be used in the place of the costly conventional manufacturing. In addition to cost effectiveness $3 \mathrm{D}$ printing allows to develop complex structures with specific features of antennas for demanding applications. With the help of SRR, biodegradable PLA and cost-effective 3D printing technique Kumar et al. [218], recently demonstrated the design and development of star shaped dielectric resonator antenna (SDRA). They reported that a special type of polymer called PLA is fabricated by additive manufacturing technique using renewable energy sources. In addition, SDRA shows high bandwidth of $37 \%$ that can be attained by modifying the shape of rectangular DRA. Further, the circular shaped SRR can serve as a metamaterial which lead to enhancement in gain, the maximum gain attained by the antenna is of $82.7 \%$. Moreover, within in the operating band the proposed antenna exhibits the average efficiency of $80.51 \%$ and is circularly polarized at $5.8 \mathrm{GHz}$. Therefore, the outcomes are evidenced that the proposed antenna fulfils the WLAN bandwidth requirements $(5.15-5.35 \mathrm{GHz}$ and $5.725-5.825 \mathrm{GHz})$. This is useful in communication, C-band (aeronautical and meteorological radio navigation and satellite navigation systems.

In addition, the metamaterials are widely used in reduce the size of the antennas to attain multiband frequency response [219]. Negative order and zeroth order resonances are useful to design miniaturized antennas which are very useful in wireless vehicular communication systems [220-223]. Mehdipour et al. [224] demonstrated the design and applications of monopole antennas that are loaded by complementary split ring resonators (CSRR) and zeroth order resonator units. The proposed antennas can be operated in three tunable frequency bands. They reported that, the miniaturization of the proposed antenna is achieved by loading the zeroth order resonators. In addition, they observed the good agreement between the simulated and experimental results. Hence, the multi-band tunable response and miniaturized structure of the proposed antenna evinced that it is a prominent candidate for vehicular communication system. Further, Elwi [225] introduced a novel cylindrical antenna with miniaturized structure for multi-input and multi output systems. The proposed antenna consists a cylindrical shaped Kodak photo paper substrate (with height $\lambda_{\mathrm{o}} / 4.5$ and diameter $\lambda_{\mathrm{o}} / 4.5$, where $\lambda_{\mathrm{o}}$ is the wavelength of the free space at $2.25 \mathrm{GHz}$ ) on which four omega shaped monopoles (the separation between each monopole is of $\lambda_{\mathrm{o}} / 29$ ) are folded. In the frequency range 2 to $3 \mathrm{GHz}$ there exists the maximum coupling between the monopoles. The reduction in coupling is done by mounting the SRRs between the monopoles. With the help of Ink-jet deposition process the silver nanoparticles are printed on the substrate. Finally, it is observed that the proposed array shows a gain of $2.5 \mathrm{~dB}$ with wide radiation patterns which is suitable for the applications in the systems having multi-inputs and multi outputs.

\section{Metamaterials in Energy Harvesting}

Metamaterials play a vital role in energy harvesting. As we know that acoustic energy is inexhaustible and present in the ambient environment, together with common voice, rustle of falling leaves, sound near jet plane, operating sound of large grinding machine and so on $[226,227]$. However, if the energy density is low, most of the acoustic energy 
is dissipated into thermal energy during its propagation. In recent years, the researchers are focused on energy harvesting technology to convert energy into electrical energy to power up low power electronic devices [228,229]. To scavenge and confine the acoustic energy distinct energy harvesters have been proposed [230]. The advancement of acoustic energy harvesters has begun from classic Helmholtz resonators [231], photonic crystal resonators [232], and quarter-wave resonators [233] to local acoustic metamaterials resonators [234] for large energy focusing on short structural dimensions. Wireless energy harvesting $(\mathrm{WEH})$ from electromagnetic fields is flattering an emerging technology. Recent advances in broadband rectennas for wireless power transfer (WPT) and ambient RF energy harvesting was studied by C. Song [235]. The review of wireless and battery-free platforms for collection of bio signals, biosensors and bioelectronics was done by Tucker Stuart et al. [236]. They summarize present methods to realize such device architectures and deliberates their building blocks. On-site and external energy harvesting in underground wireless was studied by Raza, U [237]. These energy harvesting methods lead to design of a competent wireless underground communication system to power underground nodes for extended field operation. Additionally, key energy harvesting tools are offered that use available energy sources in the fields like vibration, solar, and wind. In this concern, the Electromagnetic (EM)- and Magnetic Induction (MI)-based approaches are important for underground wireless communication system. Recently, WPT and energy harvesting: current status and future prospects was reviewed by J. Huang et al. [238]. A meta-material based on a cubic high-dielectric resonator (CHDR) for coupled WPT (wireless power transfer) system was studied by R. Das et al. [239], they have observed that the proposed CHDR system providing more than $90 \%$ power transfer efficiency at a distance of $0.1 \lambda$. Amongst, the photonic crystals are suitable harvesters for high frequency acoustic environment, because the Bragg scattering controls the scattering characteristics of the waves in photonic crystals and the wavelength of the harvested sound is of the order of magnitude (periodic parameters) of the scatterer.

The acoustic metamaterials alter the propagation of the wave depends on the local resonance bandgap principle. In which at a specific frequency, the propagation of the incident wave is suppressed due to interaction of the resonant modes of the structural units with the travelling wave [240]. In addition, the acoustic metamaterials exhibit special wave propagation characteristics in wave vector space, spectral space, and phase space [241,242]. In acoustic energy harvesters, the acoustic energy is focused onto piezoelectric crystal and its density is improved significantly to reach the usable magnitude. The piezoelectric material converts the incident energy into electrical energy by inverse piezoelectric effect. The generated electrical energy can be used in low power consuming devices and to power up the wireless sensor network. Different types of acoustic metamaterials have been developed for harvesting of acoustic energy. With the help of lead zirconate titanate transducer and double layered acoustic metamaterial Wang et al. [243] demonstrated the acoustic energy harvester which exhibits the maximum power of $73.1 \mathrm{nW}$ at the incident wave frequency of $318 \mathrm{~Hz}$ and pressure of $2 \mathrm{~Pa}$. In addition, using spring-mass resonators Oudich et al. [244] developed acoustic metamaterial thin-plate for harvesting of acoustic energy. The designed harvester shows large out power of $18.1 \mu \mathrm{W}$ at $519 \mathrm{~Hz}$ and $2 \mathrm{~Pa}$. Recently, Ma et al. [245] designed a two-dimensional local resonant acoustic metamaterial for energy harvesting applications. They reported that the designed energy harvester shows voltage enhancement of $950 \%$ compared to bare plate energy harvester. In addition, at resonant conditions and the sound pressure of $20 \mathrm{~Pa}$ the proposed harvester shows maximum voltage of $291 \mathrm{mV}$, average power of $28 \mu \mathrm{W}$ and power density of $1.24 \mathrm{~mW} \mathrm{~cm}^{-3}$. Further, the outdoor studies revealed that the acoustic material-based harvester shows 18 times better open circuit voltage compared to the bare plate harvester. Hence, the outstanding properties of the proposed harvester evinced that it could serve as a promising acoustic energy harvester with improved performance.

In addition, the metamaterials can also absorb and harvest electromagnetic signals. Nowadays, the investigations on the metamaterial-based absorbers have increased 
for electromagnetic signal harvesting and absorbing applications in microwave region. Landy et al. [246] in 2008 designed metamaterial-based absorber consisting of two separated resonators to harvest electromagnetic waves. In addition, for high frequency regions of $\mathrm{GHz}$ and THz, Dincer et al. [247] introduced a metamaterial-based absorber with the help of square resonator. In addition, Cheng et al. [248] investigated the polarization insensitive metamaterial-based absorber for harvesting electromagnetic energy at various frequency bands. Yagitani et al. [249] proposed and designed an electrical circuit model and mushroom-like electromagnetic band gap [250] (EBG) structures for obtaining the 2D image of distribution of RF power. Finally, Alkurt et al. [251] demonstrated a metamaterialbased absorber for energy harvesting and imaging applications. The proposed harvester is also called as $2 \times 2$ patch array antenna and microwave image detector. The unit cell of the proposed harvester is shown in Figure 4 (Figure 1 of the Ref. [251]). They reported that, in the proposed absorber, first the absorbed energy is converted into DC signal with the help of Schottky diodes. Subsequently, the obtained DC signals generate image of the absorbed power. Afterwards, they fabricated $2 \times 2$ patch array antenna and energy harvester. The outcomes of the numerical and experimental measurements are matched with one another. Hence, all these results evidenced that the proposed metamaterial-based absorber can be promising candidate for energy harvesting, imaging, crack detection, and so on.

a

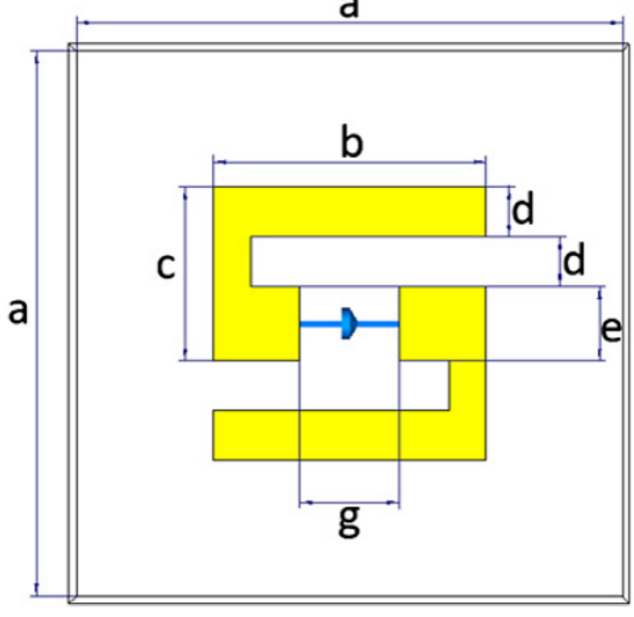

Figure 4. Unit cell of the metamaterial-based harvester (Figure 1 of Ref. [251]).

\section{Metamaterials in SQUIDs}

The investigations on the metamaterials comprising SQUIDs (Superconducting quantum interference devices) are going on intensively from the last decade [252,253]. These are the artificial materials which exhibit special properties such as negative magnetic permeability [254], dynamic multi-stability and switching [252], broad band tunability [255], etc. As we know that simple version of SQUIDs contains superconducting ring interrupted by Josephson junction [256]. The two-dimensional arrays of SQUIDs in different lattice geometries establish nonlinear metasurfaces. This can project theoretically in both quantum [257] and classical regimes $[258,259]$. By implementing this various designs and structures have been investigated in one and two dimensions [260-263]. With the help of microwave transmission measurements recently reported the degree of spatiotemporal coherence of SQUID metamaterials [264]. Further, these SQUID metamaterials provide novel testbed for exploring complex spatiotemporal dynamics. Interestingly, it is proved that SQUID metamaterials support spatially inhomogeneous states like chimera states. These chimera states gained much attention for both experimental and theoretical viewpoints $[265,266]$. In various discrete systems it was identified that different dynamic states such as solitary state chimeras [267], spiral wave chimeras [268], and imperfect chimeras [269]. In addition, the chimera states in SQUID metasurfaces controls the speed of the propagat- 
ing electromagnetic waves [270]. Lazarides et al. [271] demonstrated the generation of chimera states by SQUID metasurfaces which are subjected to dc-flux gradient and driven by ac-flux. Figure 5 shows the schematic representation of SQUID metamaterial (Figure from Ref. [271]). They reported that the flux gradient of dc-field and amplitude of the ac-flux controls desynchronized clusters of chimera state along with their location and size. Further, the chimera states are distinguished from non-chimera states by ac driving flux. Finally, the proposed SQUID oscillator is an example for system with inertia and driving which plays a prominent role in the advancement of metamaterials science. In addition, J. Hizanidis et al. [272] presented 2D SQUID lattice with nearest neighbour interactions which can form states with Turning-like pattern. In general, single SQUID undergoes complex bifurcations at low coupling limit, where as in 2D SQUID the Turning like pattern arises near synchronization to desynchronization transformation region. Further, owing to extreme multi-stability of single SQUID, 2D chimera states have formed at near resonant regime. The formed chimera states can be tuned by dc-flux also control their position and multiplicity. Finally, recent reports revealed that the imaging of the chimera states in SQUID metamaterials is prominent candidates for verifying the theoretical findings [273].

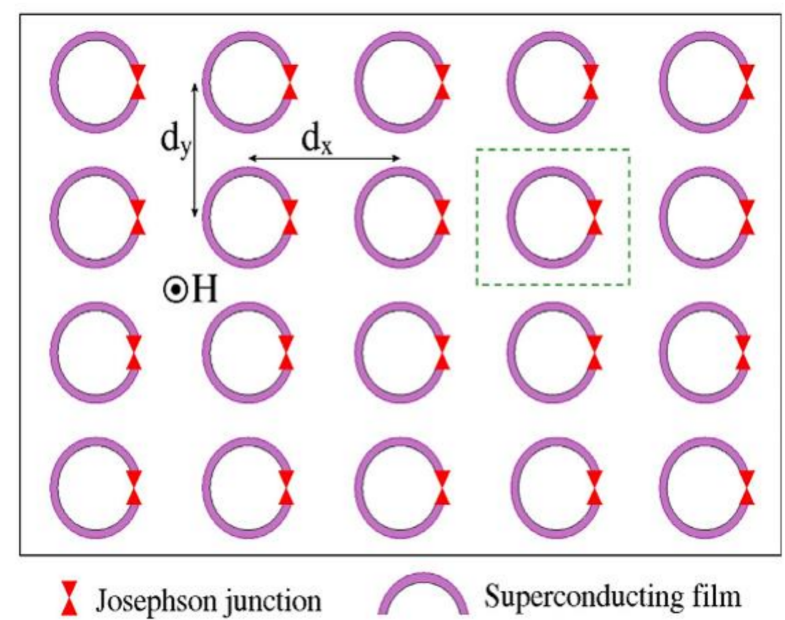

Figure 5. Schematic representation of SQUID metamaterial (Figure from Ref. [271]).

\section{Conclusions}

Metamaterials are the advanced engineered materials which offer the naturally unobtainable properties. Due to their unique behaviour the metamaterials gained considerable attention in various fields including sensors, energy harvesting, photonics, and so on. Graphene based metamaterials efficiently can control absorption/transmission/reflection of electromagnetic waves. The graphene assisted $\mathrm{THz}$ metamaterial sensing platform is suitable for biological sensing applications. Even though, massive research is going on to search new kind of tunable metamaterials with improved performance, significant challenges remain. The star shaped dielectric resonator antenna (SDRA) achieves the WLAN bandwidth requirements $(5.15-5.35 \mathrm{GHz}$ and $5.725-5.825 \mathrm{GHz})$. This is useful in communication, like aeronautical and meteorological radio navigation and satellite navigation systems (c-band). However, in comparison with the normal materials the metamaterials exhibit superior properties. The electrical energy generated by energy harvesting metamaterial can be used in low power consuming devices and to power up the wireless sensor network. Lead zirconate titanate transducer and double layered acoustic energy harvester exhibits the maximum power of $73.1 \mathrm{nW}$ at the incident wave frequency of $318 \mathrm{~Hz}$ and pressure of $2 \mathrm{~Pa}$. Metamaterial-based absorbers have increased for electromagnetic signal harvesting and absorbing applications in microwave region. The image of chimera states of SQUID metamaterials is prominent applicants for verifying the theoretical findings. Finally, with the rapid advancement of relevant science and technology in recent years, 
metamaterials have been developed in the direction of a standard technology platform to accomplish basic tunability and advanced application of metamaterial devices.

Author Contributions: Conceptualization, N.S.K. and K.C.B.N.; methodology, N.S.K.; validation, N.S.K., K.C.B.N., P.B. and T.A.B.; resources, B.V.S.R.; data curation, T.A.B.; writing-original draft preparation, N.S.K.; writing-review and editing, K.C.B.N.; visualization, B.V.S.R.; supervision, N.S.K.; project administration, K.C.B.N.; funding acquisition, P.B. All authors have read and agreed to the published version of the manuscript.

Funding: One of us P. Banerjee received UGC, India start-up grant no F.30-457/2018 (BSR).

Institutional Review Board Statement: Not applicable for studies not involving humans or animals.

Informed Consent Statement: Not applicable for studies not involving humans or animals.

Data Availability Statement: The data will be made immediately available based on the request.

Acknowledgments: The authors express thankfulness to P. Sreeramulu, (English), GITAM, Bangalore for providing English language editing services to this manuscript.

Conflicts of Interest: The authors declare that we have no conflicts of interest.

\section{References}

1. Pendry, J.B. Negative refraction makes a perfect lens. Phys. Rev. Lett. 2000, 85, 3966. [CrossRef] [PubMed]

2. Papasimakis, N.; Fedotov, V.A.; Zheludev, N.I.; Prosvirnin, S.L. Metamaterial analog of electromagnetically induced transparency. Phys. Rev. Lett. 2008, 101, 253903. [CrossRef] [PubMed]

3. Kurter, C.; Tassin, P.; Zhang, L.; Koschny, T.; Zhuravel, A.P.; Ustinov, A.V.; Anlage, S.M.; Soukoulis, C.M. Classical analogue of electromagnetically induced transparency with a metal-superconductor hybrid metamaterial. Phys. Rev. Lett. 2011, $107,043901$. [CrossRef] [PubMed]

4. Jin, B.B.; Wu, J.B.; Zhang, C.H.; Jia, X.Q.; Jia, T.; Kang, L.; Chen, J.; Wu, P.H. Enhanced slow light in superconducting electromagnetically induced transparency metamaterials. Supercond Sci. Technol. 2013, 26, 074004. [CrossRef]

5. Zhang, C.; Wu, J.; Jin, B.; Jia, X.; Kang, L.; Xu, W.; Wang, H.; Chen, J.; Tonouchi, M.; Wu, P. Tunable electromagnetically induced transparency from a superconducting terahertz metamaterial. Appl. Phys. Lett. 2017, 110, 241105. [CrossRef]

6. Schurig, D.; Mock, J.J.; Justice, B.J.; Cummer, S.A.; Pendry, J.B.; Starr, A.F.; Smith, D.R. Metamaterial electromagnetic cloak at microwave frequencies. Science 2006, 314, 977-980. [CrossRef]

7. Linden, S.; Enkrich, C.; Dolling, G.; Klein, M.W.; Zhou, J.; Koschny, T.; Soukoulis, C.M.; Burger, S.; Schmidt, F.; Wegener, M. Photonic Metamaterials: Magnetism at Optical Frequencies. IEEE J. Sel. Top. Quantum Electron. 2006, 12, 1097-1105. [CrossRef]

8. Li, C.; Wu, J.; Jiang, S.; Su, R.; Zhang, C.; Jiang, C.; Zhou, G.; Jin, B.; Kang, L.; Xu, W.; et al. Electrical dynamic modulation of THz radiation based on superconducting metamaterials. Appl. Phys. Lett. 2017, 111, 092601. [CrossRef]

9. Shelby, R.A.; Smith, D.R.; Schultz, S. Experimental verification of a negative index of refraction. Science 2001, 292, 77-79. [CrossRef]

10. Zheludev, N.I. The road ahead for metamaterials. Science 2010, 328, 582-583. [CrossRef]

11. Zheludev, N.I. A Roadmap for Metamaterials. Opt. Photonics News 2011, 22, 31-35. [CrossRef]

12. Tong, X.C. Science; Springer International Publishing AG: New York, NY, USA, 2018; Volume 262.

13. Engheta, N.; Ziolkowski, R. Metamaterials: Physics and Engineering Explorations; John Wiley \& Sons: New York, NY, USA, 2006; ISBN 9780471784180.

14. Capolino, F. Theory and Phenomena of Metamaterials: Metamaterials Handbook; CRC Press: Boca Raton, FL, USA, 2017; ISBN1 1420054260. ISBN2 9781420054262.

15. Smith, D.R.; Padilla, W.J.; Vier, D.C.; Nemat-Nasser, S.C.; Schultz, S. Composite Medium with Simultaneously Negative Permeability and Permittivity. Phys. Rev. Lett. 2000, 84, 4184-4187. [CrossRef] [PubMed]

16. Veselago, V.G. The Electrodynamics of Substances with Simultaneously Negative Values of $\varepsilon$ and $\mu$. Usp. Fiz. Nauk. 1967, 92, 517-526. [CrossRef]

17. Pendry, J.B.; Holden, A.J.; Robbins, D.J.; Stewart, W.J. Magnetism from Conductors, and Enhanced Non-linear Phenomena. IEEE Trans. Microw. Theory Tech. 1999, 47, 2075-2084. [CrossRef]

18. Lalas, A.X.; Kantartzis, N.V.; Tsiboukis, T.D. Metamaterial-based wireless power transfer through interdigitated SRRs. COMPEL:Int. J. Comput. Math. Electr. Electron. Eng. 2016, 35, 1338-1345. [CrossRef]

19. Pendry, J.B.; Holden, A.J.; Stewart, W.J.; Youngs, I. Extremely Low Frequency Plasmons in Metallic Mesostructures. Phys. Rev. Lett. 1996, 76, 4773-4776. [CrossRef] [PubMed]

20. Manufacturing Disruption. Available online: https://manufacturingdisruption.com/2014/12/31/metamaterials-ultimatecomposites / (accessed on 4 May 2021).

21. Ziolkowski, R.W. Design, Fabrication, and Testing of Double Negative Metamaterials. IEEE Trans. Antennas Propag. 2003, 51, 1516-1529. [CrossRef] 
22. Shamonina, E.; Solymar, L. Magneto-inductive waves supported by metamaterial elements: Components for a one-dimensional waveguide. J. Phys. D Appl. Phys. 2004, 37, 362-367. [CrossRef]

23. Butz, S.; Jung, P.; Filippenko, L.V.; Koshelets, V.P.; Ustinov, A.V. A one-dimensional tunable magnetic metamaterial. Opt. Express 2013, 21, 22540-22548. [CrossRef]

24. Zagoskin, A.M. Superconducting quantum metamaterials in 3D: Possible realizations. J. Opt. 2012, 14, 114011. [CrossRef]

25. Mawatari, Y.; Navau, C.; Sanchez, A. Two-dimensional arrays of superconducting strips as dc magnetic metamaterials. Phys. Rev. B 2012, 85, 134524. [CrossRef]

26. Kafesaki, M.; Tsiapa, I.; Katsarakis, N.; Koschny, T.; Soukoulis, C.M.; Economou, E.N. Left-handed meta-materials: The fishnet structure and its variations. Phys. Rev. B 2007, 75, 235114. [CrossRef]

27. Wuestner, S.; Pusch, A.; Tsakmakidis, K.L.; Hamm, J.M.; Hess, O. Overcoming losses with gain in a negative refractive index metamaterial. Phys. Rev. Lett. 2010, 127401. [CrossRef]

28. Liu, N.; Guo, H.; Fu, L.; Kaiser, S.; Schweizer, H.; Giessen, H. Three-dimensional photonic metamaterials at optical frequencies. Nat. Mater. 2008, 7, 31-37. [CrossRef] [PubMed]

29. Valentine, J.; Zhang, S.; Zentgraf, T.; Ulin-Avila, E.; Genov, D.A.; Bartal, G.; Zhang, X. Three-dimensional optical metamaterial with a negative refractive index. Nature 2008, 455, 376-379. [CrossRef]

30. Altintas, O.; Aksoy, M.; Akgol, O.; Unal, E.; Karaaslan, M.; Sabah, C. Fluid, Strain and Rotation Sensing Applications by Using Metamaterial Based Sensor. J. Electrochem. Soc. 2017, 164, B567-B573. [CrossRef]

31. Abdulkarim, Y.I.; Deng, L.; Altintas, O.; Unal, E.; Karaaslan Physica, M. Low-Dimens, E. Metamaterial absorber sensor design by incorporating swastika shaped resonator to determination of the liquid chemicals depending on electrical characteristics. Syst. Nanostruct. 2019, 114, 113593.

32. Bakir, M.; Dalgaç, Ş.; Karaaslan, M.; Karada, F.; Akgol, O.; Unal, E.; Depçi, T.; Sabah, C. A comprehensive study on fuel adulteration sensing by using triple ring resonator type metamaterial. J. Electrochem. Soc. 2019, 166, B1044-B1052. [CrossRef]

33. Fang, N.; Zhang, X. Rapid growth of evanescent wave by a silver superlens. Appl. Phys. Lett. 2003, 82, 161-163. [CrossRef]

34. Zhu, J.; Eleftheriades, G.V. Dual-band metamaterial-inspired small monopole antenna for WiFi applications. Electron. Lett. 2009, 45, 1104-1106. [CrossRef]

35. Erentok, A.; Ziolkowski, R.W. Metamaterial-Inspired Efficient Electrically Small Antenna. IEEE Trans. Antennas Propag. 2008, 56, 691-707. [CrossRef]

36. Aydin, K.; Bulu, I.; Ozbay, E. Subwavelength resolution with a negative-index metamaterial superlens. Appl. Phys. Lett. 2007, 90, 254102. [CrossRef]

37. Hu, T.; Landy, N.I.; Bingham, C.M.; Zhang, X.; Averitt, R.D.; Padilla, W.J. A metamaterial absorber for the terahertz regime: Design, fabrication and characterization. Opt. Express 2008, 16, 7181-7188.

38. Dincer, F.; Karaaslan, M.; Sabah, C. Design and analysis of perfect metamaterial absorber in GHz and THz Frequencies. J. Electromagn. Waves Appl. 2015, 29, 2492-2500. [CrossRef]

39. Li, M.; Yang, H.L.; Hou, X.W.; Tian, Y.; Hou, D.Y. Perfect Metamaterial Absorber with Dual Bands. Prog. Electromagn. Res. 2010, 108, 37-49. [CrossRef]

40. Ma, Y.; Chen, Q.; Grant, J.; Saha, S.C.; Khalid, A.; Cumming, D.R. A terahertz polarization insensitive dual band metamaterial absorber. Opt. Lett. 2011, 36, 945-947. [CrossRef]

41. Watts, C.M.; Liu, X.; Padilla, W.J. Metamaterial electromagnetic wave absorbers. Adv. Mater. 2012, 24, OP98-OP120. [CrossRef]

42. Akgol, O.; Altintas, O.; Dalkilinc, E.E.; Unal, E.; Karaaslan, M.; Sabah, C. Metamaterial absorber-based multisensor applications using a meander-line resonator. Opt. Eng. 2017, 56, 087104. [CrossRef]

43. Bagmanci, M.; Karaaslan, M.; Unal, E.; Özaktürk, M.; Akgol, O.; Karadag, F.; Bhadauria, A.; Bakir, M. Wide band fractal-based perfect energy absorber and power harvester. Int. J. RF Microw. Comput. Aided Eng. 2019, 29, e21597. [CrossRef]

44. Mulla, B.; Sabah, C. Multiband metamaterial absorber design based on plasmonic resonances for solar energy harvesting. Plasmonics 2016, 11, 1313-1321. [CrossRef]

45. Zheludev, N.I.; Kivshar, Y.S. From metamaterials to metadevices. Nat. Mater. 2012, 11, 917-924. [CrossRef]

46. Wang, Z.; Cheng, F.; Winsor, T.; Liu, Y. Optical chiral metamaterials: A review of the fundamentals, fabrication methods and applications. Nanotechnology 2016, 27, 412001. [CrossRef]

47. Qiu, M.; Zhang, L.; Tang, Z.; Jin, W.; Qiu, C.-W.; Lei, D.Y.3D metaphotonic nanostructures with intrinsic chirality. Adv. Funct. Mater. 2018, 28, 1803147. [CrossRef]

48. Gansel, J.K.; Thiel, M.; Rill, M.S.; Decker, M.; Bade, K.; Saile, V.; von Freymann, G.; Linden, S.; Wegener, M. Gold helix photonic metamaterial as broadband circular polarizer. Gold Helix Sci. 2009, 325, 1513-1515. [CrossRef]

49. Gao, W.; Leung, H.M.; Li, Y.; Chen, H.; Tam, W.Y.J. Circular dichroism in double-layer metallic crossed-gratings. Optics 2011, 13, 115101.

50. Yin, X.; Schäferling, M.; Michel, A.-K.U.; Tittl, A.; Wuttig, M.; Taubner, T.; Giessen, H. Active Chiral Plasmonics. Nano Lett. 2015, 15, 4255-4260. [CrossRef]

51. Wu, C.; Arju, N.; Kelp, G.; Fan, J.A.; Dominguez, J.; Gonzales, E.; Tutuc, E.; Brener, I.; Shvets, G. Spectrally selective chiral silicon metasurfaces based on infrared Fano resonances. Nat. Commun. 2014, 5, 3892. [CrossRef] [PubMed]

52. Wang, Z.; Jia, H.; Yao, K.; Cai, W.; Chen, H.; Liu, Y. Circular dichroism metamirrors with near-perfect extinction. ACS Photonics 2016, 3, 2096-2101. [CrossRef] 
53. Li, W.; Coppens, Z.J.; Besteiro, L.V.; Wang, W.; Govorov, A.O.; Valentine, J. Circularly polarized light detection with hot electrons in chiral plasmonic metamaterials. Nat. Commun. 2015, 6, 8379. [CrossRef] [PubMed]

54. Kang, L.; Rodrigues, S.P.; Taghinejad, M.; Lan, S.; Lee, K.-T.; Liu, Y.; Werner, D.H.; Urbas, A.; Cai, W. Preserving spin states upon reflection: Linear and nonlinear responses of a chiral meta-mirror. Nano Lett. 2017, 17, 7102-7109. [CrossRef] [PubMed]

55. Taghvaee, H.; Abadal, S.; Pitilakis, A.; Tsilipakos, O.; Tasolamprou, A.; Liaskos, C.K.; Kafesaki, M.; Kantartzis, N.V.; CabellosAparicio, A.; Alarcón, E. Scalability Analysis of Programmable Metasurfaces for Beam Steering. IEEE Access 2020, 8, 105320-105334. [CrossRef]

56. Kang, L.; Wang, C.-Y.; Guo, X.; Ni, X.; Liu, Z.; Werner, D.H. Nonlinear chiral meta-mirrors: Enabling technology for ultrafast switching of light polarization. Nano Lett. 2020, 20, 2047-2055. [CrossRef] [PubMed]

57. Olsson, R.H.; El-Kady, I. Microfabricated phononic crystal devices and applications. Meas. Sci. Technol. 2009, 20, 012002. [CrossRef]

58. Baboly, M.G.; Soliman, Y.M.F.; Reinke, M.; Leseman, Z.C.; El-Kady, I. Demonstration of acoustic waveguiding and tight bending in phononic crystals. Appl. Phys. Lett. 2016, 109, 183504. [CrossRef]

59. Hasan, M.Z.; Kane, C.L. Colloquium: Topological insulators. Rev. Mod. Phys. 2010, 82, 3045-3067. [CrossRef]

60. Nash, L.M.; Kleckner, D.; Read, A.; Vitelli, V.; Turner, A.M.; Irvine, W.T.M. Topological mechanics of gyroscopic metamaterials. Proc. Natl. Acad. Sci. USA 2015, 112, 14495-14500. [CrossRef]

61. Mitchell, N.P.; Nash, L.M.; Hexner, D.; Turner, A.M.; Irvine, W.T.M. Amorphous topological insulators constructed from random point sets. Nat. Phys. 2018, 14, 380-385. [CrossRef]

62. Süsstrunk, R.; Huber, S.D. Observation of phononic helical edge states in a mechanical topological insulator. Science 2015, 349, 47-50. [CrossRef] [PubMed]

63. Serra-Garcia, M.; Peri, V.; Süsstrunk, R.; Bilal, O.R.; Larsen, T.; Villanueva, L.G.; Huber, S.D. Observation of a phononic quadrupole topological insulator. Nature 2018, 555, 342-345. [CrossRef]

64. Yu, S.; He, C.; Wang, Z.; Liu, F.-K.; Sun, X.-C.; Li, Z.; Lu, H.-Z.; Lu, M.-H.; Liu, X.-P.; Chen, Y.-F. Elastic pseudospin transport for integratable topological phononic circuits. Nat. Commun. 2018, 9, 3072. [CrossRef]

65. Peano, V.; Brendel, C.; Schmidt, M.; Marquardt, F. Topological phases of sound and light. Phys. Rev. 2015, X5, 031011. [CrossRef]

66. Brendel, C.; Peano, V.; Painter, O.J.; Marquardt, F. Snowflake phononic topological insulator at the nanoscale. Phys. Rev. 2018, B97, 020102. [CrossRef]

67. Cha, J.; Kim, K.W.; Daraio, C. Experimental realization of on-chip topological nanoelectromechanical metamaterials. Nature 2018, 564, 229-233. [CrossRef]

68. Cho, C.; Wen, X.; Park, N.; Li, J. Digitally virtualized atoms for acoustic metamaterials. Nat. Commun. 2020, 11, 251. [CrossRef] [PubMed]

69. Forster, T.Z. Experimentelle und theoretische Untersuchung des zwischenmolekularen Übergangs von Elektronenanregungsenergie. Naturforsch. A 1949, 4, 321. [CrossRef]

70. Scholes, G.D. Long-range resonance energy transfer in molecular systems. Annu. Rev. Phys. Chem. 2003, 54, 57-87. [CrossRef] [PubMed]

71. Hardin, B.E.; Hoke, E.T.; Armstrong, P.B.; Yum, J.-H.; Comte, P.; Torres, T.; Frechet, J.M.; Nazeeruddin, M.K.; Gratzel, M.; McGehee, M.D. Increased light harvesting in dye-sensitized solar cells with energy relay dyes. Nat. Photonics $2009,3,406-411$. [CrossRef]

72. Baldo, M.A.; O’brien, D.; You, Y.; Shoustikov, A.; Sibley, S.; Thompson, M.; Forrest, S. Highly efficient phosphorescent emission from organic electroluminescent devices. Nature 1998, 395, 151-154. [CrossRef]

73. van Grondelle, R.; Dekker, J.P.; Gillbro, T.; Sundstrom, V. Energy transfer and trapping in photosynthesis. Biochim. Biophys. Acta Bioenerg. 1994, 1187, 1-65. [CrossRef]

74. Tumkur, T.U.; Kitur, J.K.; Bonner, C.E.; Poddubny, A.N.; Narimanov, E.E.; Noginov, M.A. Control of Förster energy transfer in the vicinity of metallic surfaces and hyperbolic metamaterials. Faraday Discuss. 2015, 178, 395-412. [CrossRef]

75. Cortes, C.L.; Jacob, Z. Super-Coulombic atom-atom interactions in hyperbolic media. Nat. Commun. 2017, 8, 14144. [CrossRef]

76. Ren, J.; Wu, T.; Yang, B.; Zhang, X. Simultaneously giant enhancement of Förster resonance energy transfer rate and efficiency based on plasmonic excitations. Phys. Rev. B Condens. Matter Mater. Phys. 2016, 94, 125416. [CrossRef]

77. Martín-Cano, D.; Martín-Moreno, L.; García-Vidal, F.J.; Moreno, E. Resonance energy transfer and superradiance mediated by plasmonic nanowaveguides. Nano Lett. 2010, 10, 3129-3134. [CrossRef] [PubMed]

78. Bouchet, D.; Cao, D.; Carminati, R.; De Wilde, Y.; Krachmalnic off, V. Long-range plasmon-assisted energy transfer between fluorescent emitters. Phys. Rev. Lett. 2016, 116, 037401. [CrossRef]

79. Biehs, S.-A.; Menon, V.M.; Agarwal, G.S. Long-range dipole-dipole interaction and anomalous Förster energy transfer across a hyperbolic metamaterial. Phys. Rev. B Condens. Matter Mater. Phys. 2016, 93, 245439. [CrossRef]

80. Deshmukh, R.; Biehs, S.-A.; Khwaja, E.; Galfsky, T.; Agarwal, G.S.; Menon, V.M. Long-range resonant energy transfer using optical topological transitions in metamaterials. ACS Photonics 2018, 5, 2737-2741. [CrossRef]

81. Kruk, S.S.; Wong, Z.J.; Pshenay-Severin, E.; O’Brien, K.; Neshev, D.N.; Kivshar, Y.S.; Zhang, X. Magnetic hyperbolic optical metamaterials. Nat. Commun. 2016, 7, 11329. [CrossRef]

82. Mirmoosa, M.S.; Kosulnikov, S.Y.; Simovski, C.R. Magnetic hyperbolic metamaterial of high-index nanowires. Phys. Rev. B 2016, 94, 075138. [CrossRef] 
83. Papadaki, G.T.; Fleischma, D.; Davoyan, A.; Yeh, A.; Atwater, H.A. Optical magnetism in planar metamaterial heterostructures. Nat. Commun. 2018, 9, 296. [CrossRef] [PubMed]

84. Yang, Y.H.; Qin, P.F.; Zheng, B.; Shen, L.; Wang, H.P.; Wang, Z.J.; Li, E.P.; Singh, R.; Chen, H.S. Hyperbolic metamaterials: From dispersion manipulation to applications. Adv. Sci. 2018, 5, 1801495. [CrossRef]

85. Iorsh, I.V.; Poddubny, A.N.; Ginzburg, P.; Belov, P.A.; Kivshar, Y.S. Compton-like polariton scattering in hyperbolic metamaterials. Phys. Rev. Lett. 2015, 114, 185501. [CrossRef]

86. Shen, H.; Lu, D.; VanSaders, B.; Kan, J.J.; Xu, H.X.; Fullerton, E.E.; Liu, Z.W. Anomalously Weak Scattering in Metal-Semiconductor Multilayer Hyperbolic Metamaterials. Phys. Rev. 2015, X5, 021021. [CrossRef]

87. Qian, C.; Lin, X.; Yang, Y.; Gao, F.; Shen, Y.C.; Lopez, J.; Kaminer, I.; Zhang, B.L.; Li, E.P.; Soljacic, M.; et al. Multifrequency superscattering from subwavelength hyperbolic structures. ACS Photonics 2018, 5, 1506. [CrossRef]

88. Rituraj; Catrysse, P.B.; Fan, S.H. Scattering of electromagnetic waves by cylinder inside uniaxial hyperbolic medium. Opt. Express 2019, 27, 3991.

89. Memarian, M.; Eleftheriades, G.V. Light concentration using hetero-junctions of anisotropic low permittivity metamaterials. Light Sci. Appl. 2013, 2, e114. [CrossRef]

90. Guo, Z.W.; Jiang, H.T.; Zhu, K.J.; Sun, Y.; Li, Y.H.; Chen, H. Focusing and super-resolution with partial cloaking based on linear-crossing metamaterials. Phys. Rev. Appl. 2018, 10, 064048. [CrossRef]

91. Yang, Y.T.; Jia, Z.Y.; Xu, T.; Luo, J.; Lai, Y.; Hang, Z.H. Beam splitting and unidirectional cloaking using anisotropic zero-index photonic crystals. Appl. Phys. Lett. 2019, 114, 161905. [CrossRef]

92. Naik, G.V.; Liu, J.; Kildishev, A.V.; Shalaev, V.M.; Boltasseva, A. Demonstration of Al: ZnO as a plasmonic component for near-infrared metamaterials. Proc. Natl. Acad. Sci. USA 2012, 109, 8834. [CrossRef] [PubMed]

93. Xu, T.; Agrawal, A.; Abashin, M.; Chau, K.J.; Lezec, H.J. All-angle negative refraction and active flat lensing of ultraviolet light. Nature 2013, 497, 470. [CrossRef]

94. Argyropoulos, C.; Estakhri, N.M.; Monticone, F.; Alù, A. Negative refraction, gain and nonlinear effects in hyperbolic metamaterials. Opt. Express 2013, 21, 15037. [CrossRef]

95. High, A.A.; Devlin, R.C.; Dibos, A.; Polking, M.; Wild, D.S.; Perczel, J.; de Leon, N.P.; Lukin, M.D.; Park, H. Visible-frequency hyperbolic metasurface. Nature 2015, 522, 192. [CrossRef] [PubMed]

96. Sheng, C.; Liu, H.; Chen, H.Y.; Zhu, S.N. Definite photon deflections of topological defects in metasurfaces and symmetry-breaking phase transitions with material loss. Nat. Commun. 2018, 9, 4271. [CrossRef]

97. Smith, D.R.; Schurig, D. Electromagnetic wave propagation in media with indefinite permittivity and permeability tensors. Phys. Rev. Lett. 2003, 90, 077405. [CrossRef]

98. Smith, D.R.; Schurig, D.R.; Mock, J.J.; Kolinko, P.; Rye, P. Partial focusing of radiation by a slab of indefinite media. Appl. Phys. Lett. 2004, 84, 2244. [CrossRef]

99. Noginov, M.A.; Li, H.; Barnakov, Y.A.; Dryden, D.; Nataraj, G.; Zhu, G.; Bonner, C.E.; Mayy, M.; Jacob, Z. ZEE Narimanov, Controlling spontaneous emission with metamaterials. Opt. Lett. 2010, 35, 1863-1865. [CrossRef]

100. Jacob, Z.; Kim, J.; Naik, G.; Boltasseva, A.; Narimanov, E.; Shalaev, V. Engineering photonic density of states using metamaterials. Appl. Phys. B Lasers Opt. 2010, 100, 215-218. [CrossRef]

101. Smolyaninov, I.I. Giant Unruh effect in hyperbolic metamaterial waveguides. Opt. Lett. 2019, 44, 2224-2227. [CrossRef]

102. Tumkur, T.; Zhu, G.; Black, P.; Barnakov, Y.A.; Bonner, C.E.; Noginov, M.A. Control of spontaneous emission in a volume of functionalized hyperbolic metamaterial. Appl. Phys. Lett. 2011, 99, 151115. [CrossRef]

103. Krishnamoorthy, H.N.; Jacob, Z.; Narimanov, E.; Kretzschmar, I.; Menon, V.M. Topological transitions in metamaterials. Science 2012, 336, 205. [CrossRef] [PubMed]

104. Galfsky, T.; Krishnamoorthy, H.N.S.; Newman, W.; Narimanov, E.E.; Jacob, Z.; Menon, V.M. Active hyperbolic metamaterials: Enhanced spontaneous emission and light extraction. Optica 2015, 2, 62. [CrossRef]

105. Feng, K.J.; Sivco, D.L.; Hoffman, A.J. Engineering optical emission in sub-diffraction hyperbolic metamaterial resonators. Opt. Express 2018, 26, 4382. [CrossRef]

106. Fernandes, D.E.; Maslovski, S.I.; Silveirinha, M.G. Cherenkov emission in a nanowire material. Phys. Rev. B 2012, 85, 155107. [CrossRef]

107. Liu, F.; Xiao, L.; Ye, Y.; Wang, M.X.; Cui, K.Y.; Feng, X.; Zhang, W.; Huang, Y.D. Integrated Cherenkov radiation emitter eliminating the electron velocity threshold. Nat. Photonics 2017, 11, 289. [CrossRef]

108. Silveirinha, M. A low-energy Cherenkov glow. Nat. Photonics 2017, 11, 269. [CrossRef]

109. Tao, V.; Wu, L.; Zheng, G.X.; Yu, S.H. Cherenkov polaritonic radiation in a natural hyperbolic material. Carbon 2019, 150, 136. [CrossRef]

110. Belov, P.A.; Simovski, C.R.; Ikonen, P. Canalization of subwavelength images by electromagnetic crystals. Phys. Rev. B 2005, 71, 193105. [CrossRef]

111. Poddubny, A.; Iorsh, I.; Belov, P.; Kivshar, Y. Hyperbolic metamaterials. Nat. Photon. 2013, 7, 948-957. [CrossRef]

112. Folland, T.G.; Fali, A.; White, S.T.; Matson, J.R.; Liu, S.; Aghamiri, N.A.; Edgar, J.H.; Haglund, R.F., Jr.; Abate, Y.; Caldwell, J.D. Reconfigurable infrared hyperbolic metasurfaces using phase change materials. Nat. Commun. 2018, 9, 4371. [CrossRef] [PubMed] 
113. Yoxall, E.; Schnell, M.; Nikitin, A.Y.; Txoperena, O.; Woessner, A.; Lundeberg, M.B.; Casanova, F.; Hueso, L.E.; Koppens, F.H.L.; Hillenbrand, R. Direct observation of ultraslow hyperbolic polariton propagation with negative phase velocity. Nat. Photonics 2015, 9, 674. [CrossRef]

114. Caldwell, J.D.; Aharonovich, I.; Cassabois, G.; Edgar, J.H.; Gil, B.; Basov, D.N. Photonics with hexagonal boron nitride. Nat. Rev. Mater. 2019, 4, 552. [CrossRef]

115. Ambrosio, A.; Jauregui, L.A.; Dai, S.; Chaudhary, K.; Tamagnone, M.; Fogler, M.M.; Basov, D.N.; Capasso, F.; Kim, P.; Wilson, W.L. Mechanical detection and imaging of hyperbolic phonon polaritons in hexagonal boron nitride. ACS Nano 2017, $11,8741$. [CrossRef] [PubMed]

116. Alfaro-Mozaz, F.J.; Alonso-González, P.; Vélez, S.; Dolado, I.; Autore, M.; Mastel, S.; Casanova, F.; Hueso, L.E.; Li, P.; Nikitin, A.Y.; et al. Nanoimaging of resonating hyperbolic polaritons in linear boron nitride antennas. Nat. Commun. 2017, 8, 15624.

117. Lin, X.; Yang, Y.; Rivera, N.; López, J.J.; Shen, Y.; Kaminerb, I.; Chen, H.; Zhang, B.; Joannopoulos, J.D.; Soljacic, M. All-angle negative refraction of highly squeezed plasmon and phonon polaritons in graphene-boron nitride heterostructures. Proc. Natl. Acad. Sci. USA 2017, 114, 6717. [CrossRef] [PubMed]

118. Ma, W.; Alonso-González, P.; Li, S.; Nikitin, A.Y.; Yuan, J.; Martín-Sánchez, J.; Taboada-Gutiérrez, J.; Amenabar, I.; Li, P.; Vélez, S.; et al. In-plane anisotropic and ultra-low-loss polaritons in a natural van der Waals crystal. Nature 2018, 562, 557. [CrossRef]

119. Kruk, S.S.; Powell, D.A.; Minovich, A.; Neshev, D.N.; Kivshar, Y.S. Spatial dispersion of multilayer fishnet metamaterials. Opt. Express 2012, 20, 15100. [CrossRef]

120. Gomez-Diaz, J.S.; Tymchenko, M.; Alù, A. Hyperbolic plasmons and topological transitions over uniaxial metasurfaces. Phys. Rev. Lett. 2015, 114, 233901. [CrossRef]

121. Gomez-Diaz, J.S.; Alù, A. Flatland optics with hyperbolic metasurfaces. ACS Photonics 2016, 3, 2211. [CrossRef]

122. Wood, B.; Pendry, J.B.; Tsai, D.P. Directed subwavelength imaging using a layered metal-dielectric system. Phys. Rev. B 2006, 74, 115116. [CrossRef]

123. Avrutsky, I.; Salakhutdinov, I.; Elser, J.; Podolskiy, V. Highly confined optical modes in nanoscale metal-dielectric multilayers. Phys. Rev. B 2007, 75, 242402. [CrossRef]

124. Liu, Z.; Lee, H.; Xiong, Y.; Sun, C.; Zhang, C. Far-field optical hyperlens magnifying sub-diffraction-limited objects. Science 2007, 315, 1686. [CrossRef]

125. Iorsh, I.; Poddubny, A.; Orlov, A.; Belov, P.; Kivshar, Y.S. Spontaneous emission enhancement in metal-dielectric metamaterials. Phys. Lett. A. 2012, 376, 185-187. [CrossRef]

126. Guo, Y.; Cortes, C.L.; Molesky, S.; Jacob, S. Broadband super-Planckian thermal emission from hyperbolic metamaterials. Appl. Phys. Lett. 2012, 101, 131106. [CrossRef]

127. Biehs, S.-A.; Tschikin, M.; Ben-Abdallah, P. Hyperbolic metamaterials as an analog of a blackbody in the near field. Phys. Rev. Lett. 2012, 109, 104301. [CrossRef] [PubMed]

128. Nefedov, I.S.; Simovski, C.R. Giant radiation heat transfer through micron gaps. Phys. Rev. B 2011, 84, 195459. [CrossRef]

129. Schoche, S.; Ho, P.-H.; Roberts, J.A.; Yu, S.J.; Fan, J.A.; Falk, A.L. Mid-IR and UV-Vis-NIR Mueller matrix ellipsometry characterization of tunable hyperbolic metamaterials based on self-assembled carbon nanotubes. J. Vac. Sci. Technol. B 2020, $38,014015$. [CrossRef]

130. Hu, X.; Zheng, D.; Lin, Y.-S. Actively tunable terahertz metamaterial with single-band and dual-band switching characteristic. Appl. Phys. A 2020, 126, 1-9. [CrossRef]

131. Li, W.; Cheng, Y. Dual-band tunable terahertz perfect metamaterial absorber based on strontium titanate (STO) resonator structure. Opt. Commun. 2020, 462, 125265. [CrossRef]

132. Lu, T.; Qiu, P.; Lian, J.; Zhang, D.; Zhuang, S. Ultrathin and broadband highly efficient terahertz reflective polarization converter based on four L-shaped metamaterials. Ultrathin and broadband highly efficient terahertz reflective polarization converter based on four L-shaped metamaterials. Opt. Mater. 2019, 95, 109230. [CrossRef]

133. Li, Z.; Aydin, K.; Ozbay, E. Determination of effective constitutive parameters of bianisotropic metamaterials from reflection and transmission coefficients. Phys. Rev. E 2009, 79, 026610. [CrossRef]

134. Basharin, A.A.; Chuguevsky, V.; Volsky, N.; Kafesaki, M.; Economou, E.N. Extremely high -factor metamaterials due to anapole excitation. Phys. Rev. B 2017, 95, 035104. [CrossRef]

135. Li, Q.; Cong, L.; Singh, R.; Xu, N.; Cao, W.; Zhang, X.; Tian, Z.; Du, L.; Han, J.; Zhang, W. Monolayer graphene sensing enabled by the strong Fano-resonant metasurface. Nanoscale 2016, 8, 17278. [CrossRef] [PubMed]

136. Srivastava, Y.K.; Manjappa, M.; Cong, L.; Cao, W.; Al-Naib, I.; Zhang, W.; Singh, R. Ultrahigh-Q Fano Resonances in Terahertz Metasurfaces: Strong Influence of Metallic Conductivity at Extremely Low Asymmetry. Adv. Opt. Mater. 2016, 4, 457. [CrossRef]

137. Cong, L.; Singh, R. Symmetry-protected dual bound states in the continuum in metamaterials. Adv. Opt. Mater. $2019,7,1900383$. [CrossRef]

138. Wang, J.; Song, C.; Hang, J.; Hu, Z.; Zhang, F. Tunable Fano resonance based on grating-coupled and graphene-based Otto configuration. Opt. Express 2017, 25, 23880. [CrossRef]

139. Singh, R.; Al-Naib, I.A.I.; Koch, M.; Zhang, W. Sharp Fano resonances in THz metamaterials. Opt. Express 2011, 19, 6312. [CrossRef]

140. Cao, W.; Singh, R.; Al-Naib, I.A.I.; He, M.; Taylor, A.J.; Zhang, W. Low-loss ultra-high-Q dark mode plasmonic Fano metamaterials. Opt. Lett. 2012, 37, 3366. [CrossRef] 
141. Offermans, P.; Schaafsma, M.C.; Rodriguez, S.R.K.; Zhang, Y.; Crego-Calama, M.; Brongersma, S.H.; Rivas, J.G. Universal Scaling of the Figure of Merit of Plasmonic Sensors. ACS Nano 2011, 5, 5151. [CrossRef]

142. Zhu, W.M.; Liu, A.Q.; Bourouina, T.; Tsai, D.P.; Teng, J.H.; Zhang, X.H.; Lo, G.Q.; Kwong, D.L.; Zheludev, N.I. Microelectromechanical Maltese-cross metamaterial with tunable terahertz anisotropy. Nat. Commun. 2012, 3, 1274. [CrossRef]

143. Huang, Y.; Yan, J.; Ma, C.; Yang, G. Active tuning of the Fano resonance from a Si nanosphere dimer by the substrate effect. Nanoscale Horiz. 2019, 4, 148. [CrossRef] [PubMed]

144. Srivastava, Y.K.; Manjappa, M.; Krishnamoorthy, H.N.S.; Singh, R. Accessing the High-Q Dark Plasmonic Fano Resonances in Superconductor Metasurfaces. Adv. Opt. Mater. 2016, 4, 1875. [CrossRef]

145. Gu, J.; Singh, R.; Liu, X.; Zhang, X.; Ma, Y.; Zhang, S.; Maier, S.A.; Tian, Z.; Azad, A.K.; Chen, H.-T.; et al. Active control of electromagnetically induced transparency analogue in terahertz metamaterials. Nat. Commun. 2012, 3, 1151. [CrossRef]

146. Xiaofei, W.; Liu, G.; Xia, S.; Meng, H.; Shang, X.; He, P.; Zhai, X. Dynamically tunable Fano resonance based on graphene metamaterials. IEEE Photonics Technol. Lett. 2018, 30, 2147-2150.

147. Li, Q.; Gupta, M.; Zhang, X.; Wang, S.; Chen, T.; Singh, R.; Han, J.; Zhang, W. Active Control of Asymmetric Fano Resonances with Graphene-Silicon-Integrated Terahertz Metamaterials. Adv. Mater. Technol. 2020, 5, 1900840. [CrossRef]

148. Lin, Z.; Xu, Z.; Liu, P.; Liang, Z.; Lin, Y.-S.; Lin, Z.; Xu, Z.; Liu, P.; Liang, Z. Polarization-sensitive terahertz resonator using asymmetrical F-shaped metamaterial. Opt. Laser Technol. 2020, 121, 105826. [CrossRef]

149. Singh, M.R. Photon transparency in metallic photonic crystals doped with an ensemble of nanoparticles. Phys. Rev. A 2009, 79, 013826. [CrossRef]

150. Singh, M.R.; Davieau, K.; Carson, J.J.L. Effect of quantum interference on absorption of light in metamaterial hybrids. J. Phys. D. Appl. Phys. 2016, 49, 445103. [CrossRef]

151. Adamo, G.; MacDonald, K.F.; Fu, Y.H.; Wang, C.M.; Tsai, D.P.; de Abajo, F.G.; Zheludev, N.I. Light well: A tunable free-electron light source on a chip. Phys. Rev. Lett. 2009, 103, 113901. [CrossRef]

152. Adamo, G.; Ou, J.Y.; So, J.K.; Jenkins, S.D.; De Angelis, F.; MacDonald, K.F.; Fabrizio, D.; Ruostekoski, E.J.; Zheludev, N.I. Electron-beam-driven collective-mode metamaterial light source. Phys. Rev. Lett. 2012, 109, 217401. [CrossRef] [PubMed]

153. Wong, L.J.; Kaminer, I.; Ilic, O.; Joannopoulos, J.D.; Soljačić, M. Towards graphene plasmon-based free-electron infrared to X-ray sources. Nat. Photonics 2016, 10, 46. [CrossRef]

154. Plettner, T.; Byer, R.L. Proposed dielectric-based microstructure laser-driven undulator. Phys. Rev. Spec. Top. Accel. Beams 2008, 11, 030704. [CrossRef]

155. Rosolen, G.; Wong, L.J.; Rivera, N.; Maes, B.; Soljačić, M.; Kaminer, I. Metasurface-based multi-harmonic free-electron light source. Light Sci. Appl. 2018, 7, 64. [CrossRef] [PubMed]

156. Lu, T.; Yang, L.; Carmon, T.; Min, B. A narrow-linewidth on-chip toroid Raman laser. IEEE J. Quantum Electron. 2011, 47, 320. [CrossRef]

157. England, R.J.; Noble, R.J.; Bane, K.; Dowell, D.H.; Ng, C.K.; Spencer, J.E.; Tantawi, S.; Wu, Z.; Byer, R.L.; Peralta, E.; et al. Demonstration of electron acceleration in a laser-driven dielectric microstructure. Rev. Mod. Phys. 2014, 86, 1337. [CrossRef]

158. Peralta, E.A.; Soong, K.; England, R.J.; Colby, E.R.; Wu, Z.; Montazeri, B.; McGuinness, C.; McNeur, J.; Leedle, K.J.; Walz, D. Demonstration of electron acceleration in a laser-driven dielectric microstructure. Nature 2013, 503, 91. [CrossRef] [PubMed]

159. Lukianova-Hleb, E.Y.; Ren, X.; Sawant, R.R.; Wu, X.; Torchilin, V.P.; Lapotko, D.O. On-demand intracellular amplification of chemoradiation with cancer-specific plasmonic nanobubbles. Nat. Med. 2014, 20, 778. [CrossRef] [PubMed]

160. Rousse, A.; Rischel, C.; Gauthier, J.C. Femtosecond x-ray crystallography. Rev. Mod. Phys. 2001, 73, 17. [CrossRef]

161. Koppens, F.H.; Chang, D.E.; García de Abajo, F.J. Graphene plasmonics: A platform for strong light-matter interactions. Nano Lett. 2011, 11, 3370. [CrossRef]

162. Jablan, M.; Buljan, H.; Soljačić, M. Plasmonics in graphene at infrared frequencies. Phys. Rev. B 2009, 80, 245435. [CrossRef]

163. Brar, V.W.; Jang, M.S.; Sherrott, M.; Lopez, J.J.; Atwater, H.A. Highly confined tunable mid-infrared plasmonics in graphene nanoresonators. Nano Lett. 2013, 13, 2541. [CrossRef] [PubMed]

164. Wenger, T.; Viola, G.; Fogelström, M.; Tassin, P.; Kinaret, J. Optical signatures of nonlocal plasmons in graphene. Phys. Rev. B 2016, 94, 205419. [CrossRef]

165. Fang, F.; Thongrattanasiri, S.; Schlather, A.; Liu, Z.; Ma, L.; Wang, Y.; Ajayan, P.M.; Nordlander, P.; Halas, N.J.; García de Abajo, F.J. Gated Tunability and Hybridization of Localized Plasmons in Nanostructured Graphene. ACS Nano 2013, 7, 2388. [CrossRef]

166. Novoselov, K.S.; Geim, A.K.; Morozov, S.V.; Jiang, D.; Zhang, Y.; Dubonos, S.V.; Grigorieva, I.V.; Firsov, A.A. Electric field effect in atomically thin carbon films. Science 2004, 306, 666-669. [CrossRef]

167. Geim, A.K.; Novoselov, K.S. The rise of graphene. Nat. Mater. 2007, 6, 183-191. [CrossRef] [PubMed]

168. Nair, R.R.; Blake, P.; Grigorenko, A.N.; Novoselov, K.S.; Booth, T.J.; Stauber, T.; Peres, N.M.R.; Geim, A.K. Fine Structure Constant Defines Visual Transparency of Graphene. Fine Structure Constant Defines Visual Transparency of Graphene. Science 2008, 320, 1308. [CrossRef]

169. Fiori, G.; Bonaccorso, F.; Iannaccone, G.; Palacios, T.; Neumaier, D.; Seabaugh, A.; Banerjee, S.K.; Colombo, L. Electronics based on two-dimensional materials. Nat. Nanotechnol. 2014, 9, 768779. [CrossRef] [PubMed]

170. Novoselov, K.S.; Geim, A.K.; Morozov, S.V.; Jiang, D.; Katsnelson, M.I.; Grigorieva, I.V.; Dubonos, S.V.; Firsov, A.A. Twodimensional gas of massless Dirac fermions in graphene. Nature 2005, 438, 197. [CrossRef] [PubMed] 
171. Bonaccorso, F.; Colombo, L.; Yu, G.; Stoller, M.; Tozzini, V.; Ferrari, A.C. Graphene, related two-dimensional crystals, and hybrid systems for energy conversion and storage. Science 2015, 347, 1246501. [CrossRef]

172. Koppens, F.; Mueller, T.; Avouris, P.; Ferrari, A.C.; Vitiello, M.S.; Polini, M. Photodetectors based on graphene, other twodimensional materials and hybrid systems. Nat. Nanotechnol. 2014, 9, 780. [CrossRef] [PubMed]

173. Bernardi, M.; Palummo, M.; Grossman, J.C. Extraordinary sunlight absorption and one nanometer thick photovoltaics using two-dimensional monolayer material. Nano Lett. 2013, 13, 3664. [CrossRef] [PubMed]

174. Kong, X.-T.; Khan, A.A.; Kidambi, P.R.; Deng, S.; Yetisen, A.K.; Dlubak, B.; Hiralal, P.; Montelongo, Y.; Bowen, J.; Xavier, S.; et al. Graphene-Based Ultrathin Flat Lenses. ACS Photonics 2015, 2, 200-207. [CrossRef]

175. Skulason, H.S.; Gaskell, P.E.; Szkopek, T. Optical reflection and transmission properties of exfoliated graphite from a graphene monolayer to several hundred graphene layers. Nanotechnology 2010, 21, 295709. [CrossRef] [PubMed]

176. Xiang, Y.; Dai, X.; Guo, J.; Zhang, H.; Wen, S.; Tang, D. Critical coupling with graphene-based hyperbolic metamaterials. Sci. Rep. 2015, 4, 5483. [CrossRef] [PubMed]

177. Sreekanth, K.V.; ElKabbash, M.; Alapan, Y.; Rashed, A.R.; Gurkan, U.A.; Strangi, G. A multiband perfect absorber based on hyperbolic metamaterials. Sci. Rep. 2016, 6, 26272. [CrossRef]

178. Li, W.; Valentine, J. Metamaterial perfect absorber based hot electron photodetection. Nano Lett. 2014, 14, 3510-3514. [CrossRef] [PubMed]

179. Pizzi, A.; Rosolen, G.; Wong, L.J.; Ischebeck, R.; Soljačić, M.; Feurer, T.; Kaminer, I. Graphene Metamaterials for Intense, Tunable, and Compact Extreme Ultraviolet and X-Ray Sources. Adv. Sci. 2019, 1901609. [CrossRef]

180. Ruoff, R. Calling all chemists. Graphene Nat. Nanotechnol. 2008, 3, 10-11. [CrossRef]

181. Dreyer, D.R.; Park, S.; Bielawski, C.W.; Ruoff, R.S. Graphite oxide. Chem. Soc. Rev. 2010, 39, 228-240. [CrossRef] [PubMed]

182. Chen, D.; Feng, H.; Li, J. Graphene oxide: Preparation, functionalization, and electrochemical applications. Chem. Rev. 2012, 112, 6027-6053. [CrossRef]

183. Dikin, D.A.; Stankovich, S.; Zimney, E.J.; Piner, R.D.; Dommett, G.H.B.; Evmenenko, G.; Nguyen, S.T.; Ruoff, R.S. Preparation and characterization of graphene oxide paper. Nature 2007, 448, 457. [CrossRef]

184. Eda, G.; Fanchini, G.; Chhowalla, M. Large-area ultrathin films of reduced graphene oxide as a transparent and flexible electronic material. Nat. Nanotechnol. 2008, 3, 270. [CrossRef]

185. Dong, L.; Yang, J.; Chhowalla, M.; Loh, K.P. Synthesis and reduction of large sized graphene oxide sheets. Chem. Soc. Rev. 2017, 46, 7306. [CrossRef]

186. Zhang, Y.-L.; Guo, L.; Xia, H.; Chen, Q.-D.; Feng, J.; Sun, H.-B. Photoreduction of Graphene Oxides: Methods, Properties, and Applications. Adv. Opt. Mater. 2014, 2, 10. [CrossRef]

187. Yang, Y.; Wu, J.; Xu, X.; Liang, Y.; Chu, S.T.; Little, B.E.; Morandotti, R.; Jia, B.; Moss, D.J. Enhanced four-wave mixing in waveguides integrated with graphene oxide. APL Photonics 2018, 3, 120803. [CrossRef]

188. Li, D.; Muller, M.B.; Gilje, S.; Kaner, R.B.; Wallace, G.G. Processable aqueous dispersions of graphene nanosheets. Nat. Nanotechnol. 2008, 3, 101-105. [CrossRef]

189. Ferrari, A.C. Raman spectroscopy of graphene and graphite: Disorder, electron-phonon coupling, doping and nonadiabatic effects. Solid State Commun. 2007, 143, 47. [CrossRef]

190. Yang, Y.; Lin, H.; Zhang, B.Y.; Zhang, Y.; Zhang, X.; Yu, A.; Hong, M.; Jia, B. Graphene-Based Multilayered Metamaterials with Phototunable Architecture for on-Chip Photonic Devices. ACS Photonics 2019, 6, 1033-1046. [CrossRef]

191. Zhang, Y.; Feng, Y.; Zhao, J. Graphene-enabled active metamaterial for dynamical manipulation of terahertz reflection/transmission/absorption. Phys. Lett. A 2020, 384, 12684. [CrossRef]

192. Banerjee, P.; Ghosh, G.; Biswas, S.K. Measurement of dielectric properties of medium loss samples at X-band frequencies. J. Metall. Mater. Sci. 2010, 52, 247-255.

193. Grenier, K.; Dubuc, D.; Poleni, P.; Kumemura, M.; Toshiyoshi, H.; Fujii, T.; Fujita, H. Integrated broadband microwave and microfluidic sensor dedicated to bioengineering. IEEE. Trans. Microw. Theory Tech. 2009, 57, 3246. [CrossRef]

194. Lee, H.J.; Lee, J.H.; Choi, S.; Jang, I.S.; Choi, J.S.; Jung, H.I. Asymmetric split-ring resonator-based biosensor for detection of label-free stress biomarkers. Appl. Phys. Lett. 2013, 103, 0537021. [CrossRef]

195. Rawat, V.; Dhobale, S.; Kale, S.N. Ultra-fast selective sensing of ethanol and petrol using microwave-range metamaterial complementary split-ring resonators. J. Appl. Phys. 2014, 116, 1641061. [CrossRef]

196. Gordon, J.A.; Holloway, C.L.; Booth, J.; Kim, S.; Wang, Y.; BakerJarvis, J.; Novotny, D.R. Fluid interactions with metafilms/metasurfaces for tuning, sensing, and microwave-assisted chemical processes. Phys. Rev. B 2011, 83, 205130. [CrossRef]

197. Awang, R.A.; Tovar-Lopez, F.J.; Baum, T.; Sriram, S.; Rowe, W.S. Meta-atom microfluidic sensor for measurement of dielectric properties of liquids. J. Appl. Phys. 2017, 121, 094506. [CrossRef]

198. Withayachumnankul, W.; Jaruwongrungsee, K.; Tuantranont, A.; Fumeaux, C.; Abbott, D. Metamaterial-based microfluidic sensor for dielectric characterization. Sens. Actuators A Phys. 2013, 189, 2331. [CrossRef]

199. Paris, V.; Grenier, K.; Mata-Contreras, J.; Dubuc, D.; Martín, F. Highly-sensitive microwave sensors based on open complementary split ring resonators (OCSRRs) for dielectric characterization and solute concentration measurement in liquids. IEEE Access 2018, $6,48324-48338$.

200. Xu, X.; Peng, B.; Li, D.; Zhang, J.; Wong, L.M.; Zhang, Q.; Wang, S.; Xiong, Q. Flexible visible-infrared metamaterials and their applications in highly sensitive chemical and biological sensing. Nano Lett. 2011, 11, 3232-3238. [CrossRef] 
201. Ahn, S.H.; Guo, L.J. Large-area roll-to-roll and roll-to-plate nanoimprint lithography: A step toward high-throughput application of continuous nanoimprinting. ACS Nano 2009, 3, 2304-2310. [CrossRef] [PubMed]

202. Ho, J.S.; Li, Z. Microwave Metamaterials for Biomedical Sensing, Reference Module in Biomedical Sciences; Elsevier: Amsterdam, Poland, 2021; ISBN 9780128012383. [CrossRef]

203. Kayal, S.; Shaw, T.; Mitra, D. Design of metamaterial-based compact and highly sensitive microwave liquid sensor. Appl. Phys. A 2019, 126, 1-9. [CrossRef]

204. Choi, G.; Bahk, Y.-M.; Kang, T.; Lee, Y.; Son, B.H.; Ahn, Y.H.; Seo, M.; Kim, D.-S. Terahertz nanoprobing of semiconductor surface dynamics. Nano Lett. 2017, 17, 6397-6401. [CrossRef] [PubMed]

205. Lee, D.-K.; Kang, J.-H.; Kwon, J.; Lee, J.-S.; Lee, S.; Woo, D.H.; Kim, J.H.; Song, C.-S.; Park, Q.-H.; Seo, M. Nano metamaterials for ultrasensitive Terahertz biosensing. Sci. Rep. 2017, 7, 8146. [CrossRef]

206. Xu, W.; Xie, L.; Zhu, J.; Tang, L.; Singh, R.; Wang, C.; Ma, Y.; Chen, H.-T.; Ying, Y. Terahertz biosensing with a graphenemetamaterial heterostructure platform. Carbon 2019, 141, 247-252. [CrossRef]

207. Lee, S.-H.; Choe, J.-H.; Kim, C.; Bae, S.; Kim, J.-S.; Park, Q.-H.; Seo, M. Graphene assisted terahertz metamaterials for sensitive bio-sensing. Sens. Actuators B Chem. 2020, 310, 127841. [CrossRef]

208. Eleftheriades, G.V.; Iyer, A.K.; Kremer, P.C. Planar negative refractive index media using periodically LC loaded transmission lines. IEEE Trans. Microw. Theory Technol. 2002, 50, 2702-2712. [CrossRef]

209. Abdolrazzaghi, M.; Daneshmand, M.; Iyer, A.K. Strongly enhanced sensitivity in planar microwave sensors based on metamaterial coupling. IEEE Trans. Microw. Theory Tech. 2018, 66, 1843-1855. [CrossRef]

210. Ran, L.; Huangfu, J.; Chen, H.; Li, Y.; Zhang, X.; Chen, K.; Kong, J.A. Microwave solid-state left-handed material with a broad bandwidth and an ultralow loss. Phys. Rev. B 2004, 70, 07302. [CrossRef]

211. Petosa, A.; Norwood, M.A. Artech House Antennas and Propagation Library; Artech House Publishers: Norwood, MA, USA, 2007.

212. Kumar, J.; Gupta, N. Performance analysis of dielectric resonator antennas. Wirel. Pers. Commun. 2014, 75, 1029-1049. [CrossRef]

213. Luk, K.M.; Leung, K.W. Both of the City University of Hong Kong; Research Studies Press Limited: Hertforodshire, UK, 2002.

214. Kumar, J.; Gupta, N. Bandwidth and gain enhancement technique for Gammadion cross dielectric resonator antenna. Wirel. Pers. Commun. 2015, 85, 2309-2317. [CrossRef]

215. Kumar, J.; Gupta, N. Linearly polarized asymmetric dielectric resonator antenna for 5.2-GHz WLAN applications. J. Electromagn. Waves Appl. 2015, 29, 1228-1237. [CrossRef]

216. Petosa, A.; Ittipiboon, A. Dielectric resonator antennas: A historical review and the current state of the art. IEEE Antennas Propag. Mag. 2010, 52, 91-116. [CrossRef]

217. Kumar, P.; Dwari, S.; Kumar, J. Design of biodegradable quadruple-shaped DRA for WLAN/Wi-Max applications. J. Microw. Optoelectron. Electromagn. Appl. 2017, 16, 867-880. [CrossRef]

218. Kumar, A.; Kapoor, P.; Kumar, P.; Kumar, J.; Kumar, A. Metamaterial loaded aperture coupled biodegradable star-shaped dielectric resonator antenna for WLAN and broadband applications. Microw. Opt. Technol. Lett. 2019, 62, 264-277. [CrossRef]

219. Dong, Y.; Itoh, T. Metamaterial-based antennas Metamaterial-based antennas. Proc. IEEE 2012, 100, 2271-2285. [CrossRef]

220. Gong, J.Q.; Jiang, J.B.; Liang, C.H. Low-profile folded-monopole antenna with unbalanced composite right-/left-handed transmission line. Electron. Lett. 2012, 48, 813-815. [CrossRef]

221. Iizuka, H.; Hall, P.S. Left-handed dipole antennas and their implementations. IEEE Trans. Antennas Propag. 2007, 55, 1246-1253. [CrossRef]

222. Zhu, J.; George, V.E. A compact transmission-line metamaterial antenna with extended bandwidth. IEEE Antennas Wirel. Propag. Lett. 2008, 8, 295-298.

223. Herraiz-Martínez, F.J.; Hsll, P.S.; Liu, Q.; Segovia-Vargas, D. Left-handed wire antennas over ground plane with wideband tuning. IEEE Trans. Antennas Propag. 2011, 59, 1460-1471. [CrossRef]

224. Mehdipour, A.; Denidni, T.A.; Sebak, A.R. Multi-band miniaturized antenna loaded by ZOR and CSRR metamaterial structures with monopolar radiation pattern. IEEE Trans. Antennas Propag. 2013, 62, 555-562. [CrossRef]

225. Elwi, T.A. A miniaturized folded antenna array for MIMO applications. Wirel. Pers. Commun. 2018, 98, 1871-1883. [CrossRef]

226. Sanborn, A.F.; Phillips, P.K. Scaling of sound pressure level and body size in cicadas (Homoptera: Cicadidae; Tibicinidae). Ann. Entomol. Soc. Am. 1995, 88, 479-484. [CrossRef]

227. Hart, P.J.; Hall, R.; Ray, W.; Beck, A.; Zook, J. Cicadas impact bird communication in a noisy tropical rainforest. Behav. Ecol. 2015, 26, 839-842. [CrossRef]

228. Zou, H.-X.; Zhao, L.-C.; Gao, Q.-H.; Zuo, L.; Liu, F.-R.; Tan, T.; Wei, K.-X.; Zhang, W.-M. Mechanical modulations for enhancing energy harvesting: Principles, methods and applications. Appl. Energy 2019, 255, 113871. [CrossRef]

229. Tan, T.; Yan, Z.; Lei, H. Optimization and performance comparison for galloping-based piezoelectric energy harvesters with alternating-current and direct-current interface circuits. Smart Mater. Struct. 2017, 26, 075007. [CrossRef]

230. Chen, Z.S.; Guo, B.; Yang, Y.M.; Cheng, C.C. Metamaterials-based enhanced energy harvesting: A review. Physical B 2014, 438, 1-8. [CrossRef]

231. Peng, X.; Wen, Y.M.; Li, P.; Yang, A.C.; Bai, X.L. Dynamically tunable broadband mid-infrared cross polarization converter based on graphene metamaterial. Appl. Phys. Lett. 2013, 103, 4.

232. Park, C.-S.; Shin, Y.C.; Jo, S.-H.; Yoon, H.; Choi, W.; Youn, B.D.; Kim, M. Two-dimensional octagonal phononic crystals for highly dense piezoelectric energy harvesting. Nano Energy 2018, 57. [CrossRef] 
233. Bin, L.; You, J.H.; Kim, Y.-J. Low frequency acoustic energy harvesting using PZT piezoelectric plates in a straight tube resonator. Smart Mater. Struct. 2013, 22, 055013. [CrossRef]

234. Liu, Z.; Zhang, X.; Mao, Y.; Zhu, Y.Y.; Yang, Z.; Chan, C.T.; Sheng, D.P. Locally resonant sonic materials. Science 2000, 289, 1734-1736. [CrossRef]

235. Song, C.; Huang, Y.; Zhou, J.; Carter, P. Recent advances in broadband rectennas for wireless power transfer and ambient RF energy harvesting. In Proceedings of the 2017 11th European Conference on Antennas and Propagation (EUCAP), Paris, France, 19-24 March 2017; pp. 341-345. [CrossRef]

236. Stuart, T.; Cai, L.; Burton, A.; Gutruf, P. Wireless and battery-free platforms for collection of biosignals. Biosens. Bioelectron. 2021, 178, 113007. [CrossRef]

237. Raza, U.; Salam, A. On-Site and External Energy Harvesting in Underground Wireless. Electronics 2020, 9, 681. [CrossRef]

238. Huang, J.; Zhou, Y.; Ning, Z.; Gharavi, H. Wireless Power Transfer and Energy Harvesting: Current Status and Future Prospects. IEEE Wirel. Commun. 2019, 26, 163-169. [CrossRef]

239. Das, R.; Basir, A.; Yoo, H. A Metamaterial-Coupled Wireless Power Transfer System Based on Cubic High-Dielectric Resonators. IEEE Trans. Ind. Electron. 2019, 66, 7397-7406. [CrossRef]

240. Yongmin, L.; Zhang, X. Metamaterials: A new frontier of science and technology. Chem. Soc. Rev. 2011, 40, $2494-2507$.

241. Cummer, S.A.; Christensen, J.; Alù, A. Controlling sound with acoustic metamaterials. Nat. Rev. Mater. 2016, 1, 16001. [CrossRef]

242. Chen, H.; Chan, C.T. Acoustic cloaking in three dimensions using acoustic metamaterials. Appl. Phys. Lett. 2007, 91, 183518. [CrossRef]

243. Wang, X.; Xu, J.; Ding, J.; Zhao, C.; Huang, Z. A compact and low-frequency acoustic energy harvester using layered acoustic metamaterials. Smart Mater. Struct. 2019, 28, 025035. [CrossRef]

244. Oudich, M.; Li, Y. Tunable sub-wavelength acoustic energy harvesting with a metamaterial plate. J. Phys. D Appl. Phys. 2017, 50, 315104. [CrossRef]

245. Ma, J.; Wang, Z.-H.; Liu, H.; Fan, Y.-X.; Tao, Z.-Y. Active Switching of Extremely High-Q Fano Resonances Using Vanadium Oxide-Implanted Terahertz Metamaterials. Appl. Sci. 2020, 10, 330. [CrossRef]

246. Landy, N.I.; Sajuyigbe, S.; Mock, J.J.; Smith, D.R.; Padilla, W.J. Perfect metamaterial absorber. Phys. Rev. Lett. 2008, $100,207402$. [CrossRef]

247. Chaurasiya, D.; Ghosh, S.; Bhattacharyya, S.; Srivastava, K.V. An ultrathin quad-band polarization-insensitive wide-angle metamaterial absorber. Microw. Opt. Technol. Lett. 2015, 57, 697-702. [CrossRef]

248. Cheng, Y.Z.; Fang, C.; Zhang, Z.; Wang, B.; Chen, J.; Gong, R.Z. A compact and polarization-insensitive perfect metamaterial absorber for electromagnetic energy harvesting application. In Proceedings of the Progress in Electromagnetic Research Symposium (PIERS), Shanghai, China, 8-11 August 2016; pp. 1910-1914.

249. Yagitani, S.; Katsuda, K.; Nojima, M.; Yoshimura, Y.; Sugiura, H. Imaging radio-frequency power distributions by an EBG absorber. IEICE Trans. Commun. 2011, 94, 2306-2315. [CrossRef]

250. Li, L.; Li, B.; Liu, H.-X.; Liang, C.-H. Locally resonant cavity cell model for electromagnetic band gap structures. IEEE Trans. Antennas Propag. 2006, 54, 90-100. [CrossRef]

251. Alkurt, F.O.; Altintas, O.; Ozakturk, M.; Karaaslan, M.; Akgol, O.; Unal, E.; Sabah, C. Enhancement of image quality by using metamaterial inspired energy harvester. Phy. Lett. A 2020, 384, 126041. [CrossRef]

252. Jung, P.; Ustinov, A.V.; Anlage, S.M. Progress in superconducting metamaterials. Supercond. Sci. Technol. 2014, $27,073001$. [CrossRef]

253. Banerjee, P.; Franco, A., Jr. Role of higher valent substituent on the dielectric and optical properties of $\mathrm{Sr}_{0.8} \mathrm{Bi}_{2.2} \mathrm{Nb}_{2} \mathrm{O}_{9}$ ceramics. Mater. Chem. Phys. 2019, 225, 213-218. [CrossRef]

254. Lazarides, N.; Tsironis, G.P. Multistability and self-organization in disordered SQUID metamaterials. Supercond. Sci. Technol. 2013, 26, 084006. [CrossRef]

255. Trepanier, M.; Zhang, D.; Mukhanov, O.; Anlage, S.M. Realization and modeling of metamaterials made of rf superconducting quantum-interference devices. Phys. Rev. X 2013, 3, 041029. [CrossRef]

256. Josephson, B. Possible new effects in superconductive tunnelling. Phys. Lett. A 1962, 1, 251-255. [CrossRef]

257. Du, C.; Chen, H.; Li, S. Quantum left-handed metamaterial from superconducting quantum-interference devices. Phys. Rev. $B$ 2006, 74, 113105. [CrossRef]

258. Lazarides, N.; Tsironis, G.P. RF superconducting quantum interference device metamaterials. Appl. Phys. Lett. 2007, 90, 163501. [CrossRef]

259. Fedotov, V.A.; Tsiatmas, A.; Shi, J.H.; Buckingham, R.; De Groot, P.; Chen, Y.; Zheludev, N.I. Temperature control of Fano resonances and transmission in superconducting metamaterials. Opt. Express 2010, 18, 9015-9019. [CrossRef] [PubMed]

260. Jung, P.; Butz, S.; Marthaler, M.; Fistul, M.V.; Leppäkangas, J.; Koshelets, V.P.; Ustinov, A.V. Multistability and switching in a superconducting metamaterial. Nat. Commun. 2014, 5, 3730. [CrossRef]

261. Zhang, D.; Trepanier, M.; Mukhanov, O.; Anlage, S.M. Tunable broadband transparency of macroscopic quantum superconducting metamaterials. Phys. Rev. X 2015, 5, 041045. [CrossRef]

262. Zhang, D.; Trepanier, M.; Antonsen, T.; Ott, E.; Anlage, S.M. Intermodulation in nonlinear SQUID metamaterials: Experiment and theor. Phys. Rev. B 2016, 94, 174507. [CrossRef] 
263. Kiselev, E.I.; Averkin, A.S.; Fistul, M.V.; Koshelets, V.P.; Ustinov, A.V. Two-tone spectroscopy of a SQUID metamaterial in the nonlinear regime. Phys. Rev. Res. 2019, 1, 033096. [CrossRef]

264. Trepanier, M.; Zhang, D.; Mukhanov, O.; Koshelets, V.P.; Jung, P.; Butz, S.; Ott, E.; Antonsen, T.M.; Ustinov, A.V.; Anlage, S.M. Coherent oscillations of driven rf SQUID metamaterials. Phys. Rev. E 2017, 95, 050201.

265. Saito, S.; Zhu, X.; Amsüss, R.; Matsuzaki, Y.; Kakuyanagi, K.; Shimo-Oka, T.; Mizuochi, N.; Nemoto, K.; Munro, W.J.; Semba, K. Towards realizing a quantum memory for a superconducting qubit: Storage and retrieval of quantum states. Phys. Rev. Lett. 2013, 111, 107008. [CrossRef]

266. Shulga, K.V.; Il'chev, E.; Fistul, M.V.; Besedin, I.S.; Butz, S.; Astafiev, O.V.; Hübner, U.; Ustinov, A.V. Magnetically induced transparency of a quantum metamaterial composed of twin flux qubits. Nat. Commun. 2018, 9, 150. [CrossRef]

267. Cross, M.C.; Hohenberg, P.C. Pattern formation outside of equilibrium. Rev. Mod. Phys. 1993, 65, 851. [CrossRef]

268. Showalter, K.; Epstein, I.R. From chemical systems to systems chemistry: Patterns in space and time. Chaos 2015, $25,097613$. [CrossRef]

269. Turing, A.M. The chemical basis of morphogenesis. Philos. Trans. R. Soc. B 1952, 237, 37-72.

270. Koch, A.J.; Meinhardt, H. Biological pattern formation: From basic mechanisms to complex structures. Rev. Mod. Phys. 1994, 66, 1481. [CrossRef]

271. Lazarides, N.; Tsironis, G.P. Superconducting metamaterials. Phys. Rep. 2018, 752, 1-67. [CrossRef]

272. Hizanidis, J.; Lazarides, N.; Tsironis, G.P. Pattern formation and chimera states in 2D SQUID metamaterials. Chaos 2020, 30, 013115. [CrossRef] [PubMed]

273. Zhuravel, A.P.; Bae, S.; Lukashenko, A.V.; Averkin, A.S.; Ustinov, A.V.; Anlage, S.M. Imaging collective behavior in an rf-SQUID metamaterial tuned by DC and RF magnetic fields. Appl. Phys. Lett. 2019, 114, 082601. [CrossRef] 